\title{
Wörterbuchregister. Grundlagen einer Theorie der Register in modernen Printwörterbüchern
}

\author{
Herbert Ernst Wiegand, Germanistisches Seminar, Universität Heidelberg, \\ Heidelberg, Bundesrepublik Deutschland (herbert.ernst.wiegand@gs.uni- \\ heidelberg.de)
}

\begin{abstract}
Zusammenfassung: In diesem Beitrag werden die Begriffe bereitgestellt, die benötigt werden, um jedes bereits gegebene oder noch zu planende gedruckte Wörterbuchregister in einer einheitlichen theoretischen Perspektive analysieren und entwickeln zu können, und zwar hinsichtlich seiner Strukturen, seiner Funktionen und seiner Typzugehörigkeit. Dazu werden zunächst die akzessiven Registereinträge untersucht: Zahlreiche Typen von Registereinträgen werden unterschieden, wie z.B. nach der Anzahl und nach den Typen der Registerangaben, die reduzierten, die vollständigen, die einfachen, die erweiterten und die angereicherten Registereinträge sowie nach der mediostrukturellen Orientierung u. a. die einfach und die mehrfach außenorientierten Registereinträge. Bei den Registereintragstrukturen werden hierarchische registerinterne Konstituentenstrukturen, hierarchische registerinterne Mikrostrukturen, registerinterne Adressierungsstrukturen sowie hierarchische registerinterne Angabenstrukturen dargestellt. Weiterhin wird eine Typologie von Registerzugriffsstrukturen präsentiert, in der $\mathrm{u}$. a. die mediostrukturellen von den nichtmediostrukturellen Registerzugriffsstrukturen unterschieden und beide Typen weitgehend subtypologisiert werden. Auf der Basis der unterschiedenen Eigenschaften und Teilen von Registern wird schließlich eine Typologie von Registern entworfen. Abschließend werden die Registerfunktionen betrachtet und exemplarisch gezeigt, was an Registern kritikwürdig ist.
\end{abstract}

Stichwörter: AKZESSIVER REGISTEREINTRAG, EINFACHER REGISTEREINTRAG, ERWEITERTER REGISTEREINTRAG, EXTERNE DATENAKZESSIVITÄT, GESTAFFELTE REGISTERZUGRIFFSSTRUKTUR, HIERARCHISCHE REGISTERINTERNE MIKROSTRUKTUR, MEDIOSTRUKTURELLE REGISTERZUGRIFFSSTRUKTUR, MEDIOSTRUKTURELLES REGISTER, MONODIREKTIONALES ZUGRIFFSREGISTER, PERIPHERE ALPHABETISCHE REGISTERZUGRIFFSSTRUKTUR, POLYDIREKTIONALES ZUGRIFFSREGISTER, REGISTERFUNKTION, REGISTERINTERNE ADRESSIERUNGSSTRUKTUR, REGISTERINTERNE ANGABENSTRUKTUR, ZENTRALE ALPHABETISCHE REGISTERZUGRIFFSSTRUKTUR, REGISTEREINGANG, REGISTERVERWEISANGABE，REGISTERVERWEISEINTRAG，REGISTERZUGRIFFSSTRUKTUR, WÖRTERBUCHREGISTER, ZUGRIFFSREGISTER

Abstract: Dictionary Indexes. Foundations of a Theory of Indexes in Mod-
ern-day Printed Dictionaries. This article presents the concepts needed for the analysis
and development of all existing and future dictionary indexes according to a uniform theoretical
perspective regarding their structures, functions and typology. For this purpose, the accessible
index entries are examined. Numerous types of index entries are distinguished, e.g. according to Lexikos 18 (AFRILEX-reeks/series 18: 2008): 256-302 
the number and types of index items, the reduced, the complete, the single, the expanded and the enriched index entries, as well as according to the mediostructural orientation, among others the single and the multiple externally oriented index entries. For the index entry structures, hierarchical index internal constituent structures, hierarchical index internal microstructures, index internal addressing structures as well as hierarchical index internal item structures are introduced. Furthermore a typology of index access structures is presented in which, among others, mediostructural are distinguished from the non-mediostructural index access structures and both types are extensively subtypologised. On the basis of the different features and parts of indexes a typology of indexes is proposed. In conclusion, the functions of indexes are examined and, by using examples, the aspects of indexes worthy of criticism are shown.

Keywords: ACCESS INDEX, ACCESSIBLE INDEX ENTRY, CENTRAL ALPHABETICAL INDEX ACCESS STRUCTURE, DICTIONARY INDEX, EXPANDED INDEX ENTRY, EXTERNAL DATA ACCESSIBILITY, HIERARCHICAL INDEX INTERNAL MICROSTRUCTURE, INDEX ACCESS STRUCTURE, INDEX ENTRY, INDEX FUNCTION, INDEX INTERNAL ADDRESSING STRUCTURE, INDEX INTERNAL ITEM STRUCTURE, INDEX REFERENCE ENTRY, ITEM GIVING THE INDEX CROSS-REFERENCE, MEDIOSTRUCTURAL INDEX, MEDIOSTRUCTURAL INDEX ACCESS STRUCTURE, MONODIRECTIONAL ACCESS STRUCTURE, PERIPHERAL ALPHABETICAL INDEX ACCESS STRUCTURE, POLYDIRECTIONAL ACCESS STRUCTURE, SINGLE INDEX ENTRY, STAGGERED INDEX ACCESS STRUCTURE

\section{Worum es geht und warum nicht}

In diesem Beitrag zu einem spezifischen Ausschnitt aus der Theorie der Wörterbuchform von Printwörterbüchern geht es darum, die lexikographietheoretischen Begrifflichkeiten und zugehörigen deutschen Termini sowie ihre systematischen terminologiesemantischen Beziehungen geordnet bereitzustellen, die benötigt werden, um jedes bereits gegebene oder noch zu planende gedruckte Wörterbuchregister in einer einheitlichen theoretischen Perspektive hinsichtlich seiner registerinteren Strukturen, hinsichtlich seiner Registerfunktionen und seiner typspezifischen Art als Benutzerschnittstelle zu funktionieren sowie hinsichtlich seiner Typzugehörigkeit beschreiben und planen $\mathrm{zu}$ können. Anders ausgedrückt heißt das: Es wird angestrebt, die Grundlagen für eine Theorie der Register in gedruckten Wörterbüchern zu entwickeln.

Ein solches Vorhaben ist gerade in der gegenwärtigen Entwicklung der Lexikographie insofern aktuell, als alle Formen von digitalen Wörterbüchern variable und vielseitige externe Zugriffsmöglichkeiten aufweisen, und die Printwörterbücher besonders hinsichtlich der externen Datenakzessivität (i.S.v. Wiegand 2005 u. 2008) stärkeren Beschränkungen unterworfen sind: Beschränkungen aufgrund des Datenträgers Papier, solchen aufgrund der zu wählenden Datenfixierungssysteme und nicht zuletzt solchen aufgrund eingespielter starrer lexikographischer Traditionen (vgl. u.a. Wiegand 1995: 464f). Bereits in Wiegand (1983: 442 u. 464) habe ich das Vorgehen der Lexikographen, die große Mengen von mühsam erhobenen und wertvollen Sprachdaten (relativ 
stupide) so organisieren, dass sie nur über gerade eine alphabetische makrostrukturelle Zugriffsstruktur erreichbar sind - wie z.B. im Duden-GW ironisch die "Methode der lexikographischen Datentarnung“ genannt. Damit sollte allerdings keineswegs geleugnet werden, dass Printwörterbücher nur als statische Informationssysteme hergestellt werden können. Statisch meint hier vor allem, dass die Zugriffsstrukturen aller Typen (vgl. zu diesen Wiegand 2008) textuell stets fest implementiert sind, so dass zu jedem Zugriffsstrukturtyp meistens nur ein Zugriffspfadtyp (i.S.v. Wiegand 2007) und nur selten mehrere gehören. Statisch heißt aber nicht, dass Printwörterbücher nur gerade eine äußere Zugriffsstruktur aufweisen müssen, so dass sie zum Typ des einfach direkt monoakzessiven Wörterbuchs gehören. Vielmehr kann die externe Datenakzessivität durch Register, die bestimmten Wörterbuchfunktionen zugeordnet sind (bzw. sein sollten), ganz erheblich verbessert werden. Daher ist es relevant, auf systematische Weise zu wissen und theoretisch zu verstehen, welche Möglichkeiten für die Optimierung der externen Datenakzessivität von Printwörterbüchern mit welchen Typen von Registern prinzipiell gegeben sind.

Ausdrücklich sei nun auch gesagt, worum es in diesem Beitrag nicht geht: Nicht behandelt wird der weitgefächerte Fragenkomplex, wie Register von Hand oder automatisch hergestellt werden: Die so genannte Indexierung ist ein anderes dokumentationswissenschaftliches Thema. Weiterhin verfolgt dieser Beitrag keine lexikographiehistorischen Ziele, so dass nicht darauf eingegangen wird, wie Frühformen von Wörterbuchregistern gestaltet waren und welche Funktionen sie hatten (vgl. dazu: Zedelmaier 2004; Blair 2000; Rouse und Rouse 1982).

Schließlich sei zum Abschluss dieser Vormerkung noch expressis verbis darauf hingewiesen, dass das hier skizzierte Theoriemodul zu einer Allgemeinen Theorie der Lexikographie gehört und mit anderen Modulen interagiert (vgl. Wiegand 1998: 1-10). Es ist daher nicht möglich, alle verwendeten Termini aus anderen Theoriemodulen erneut ausführlich zu erklären. Meistens können nur kurze erklärende Hinweise gegeben werden, und öfters kann ich nur auf andere Publikationen verweisen.

\section{Bauteile, Strukturen und Typen von Wörterbuchregistern}

Jeder, der Wörterbücher benutzt hat, weiß auch mehr oder weniger genau, was ein Register in einem gedruckten Wörterbuch ist. Hat man jedoch ein "Register" zu 12 Leitzordnern mit Kopien der ersten drei Seiten von "Verzeichnissen" aus über 500 Wörterbüchern (als relativ schmale empirische Basis für diese Untersuchung), dann bemerkt man allmählich, dass das praxisbasierte am prototypischen Fall orientierte, alltägliche Wissen über Register nicht einmal ausreicht, um in jedem Fall mit guten Gründen entscheiden zu können, ob ein vorgelegtes wörterbuchinternes "Verzeichnis" als Wörterbuchregister gelten soll oder nicht. Das fängt damit an, dass Wörterbuchregister unter recht unterschiedlichen Bezeichnungen firmieren, wie z.B. Register, Stichwortregister, Ele- 
mentenregister, Verzeichnis der ... (z.B. „Alphabetisches Verzeichnis der lateinischen Ursprungswörter" in Kytzler und Redemund 2007 oder "Verzeichnis nicht an alphabetischer Stelle behandelter Wörter" in Pfeifer 1993) weiterhin Bezeichnungen wie Index, Index verborum, Index rerum, Liste der ..., Rangliste der ..., Zugriffsregister, vollständiges Zugriffsregister, Umkehrwörterbuch u.a. sowie solche vom Typ „LEMMATA SACHLICH GEORDNET“ (z.B. „Entlehnungen nach Fachgebieten geordnet" in Pfeffer 1987: 21-40), und es hört damit auf, dass zwar das prototypische Wörterbuchregister im Nachspann eines Wörterbuchs zu finden ist, dass es aber auch "Verzeichnisse“ im Vorspann gibt, wie z.B. das "Sachregister - Wegweiser zum Wortschatz" in Paul (2002) oder das "Register zur lexikographisch-historischen Einführung" in Dornseiff (2004) sowie weiterhin lexikographische Register in Außentexten (vgl. Wiegand 2008), die nicht zum Buchblock eines Printwörterbuchs gehören. Aus diesen Gründen hat es daher wenig Sinn, mit einer Definition von Wörterbuchregister zu beginnen. Wir beginnen vielmehr mit exemplarischen Analysen prototypischer Wörterbuchregister (im Folgenden kurz: Register) mit dem Ziel der fortschreitenden und sich schrittweise differenzierenden Begriffsbildung.

\subsection{Akzessive Registereinträge: Bauteile, Typen und eintragsinterne Strukturen}

Akzessive Einträge (die im Englischen (basic) reference unit heißen (vgl. z.B.: Hartmann und James 1998 u. Wiegand 2003: 173ff)) sind die textuellen Basiseinheiten jedes gedruckten Nachschlagewerkes. Sie treten in nichtlexikographischen Nachschlagewerken wie Warenkataloge, Telephonbüchern, Bibliographien und von ihren Besitzern geführten Terminkalendern ebenso auf wie in allen Printwörterbüchern aller denkbaren Typen. Man unterscheidet folgende Typen von wörterbuchinternen akzessiven Einträgen: Akzessive Binnentexteinträge, akzessive Einschubeinträge, akzessive Umtexteinträge, akzessive Registereinträge und als die wichtigsten die akzessiven Wörterverzeichniseinträge, die meistens Wörterbuchartikel genannt werden. $\mathrm{Zu}$ den lexikographischen akzessiven Einträgen gehören weiterhin die wörterbuchexternen akzessiven Außentexteinträge sowie die akzessiven Listeneinträge (vgl. Wiegand 2008). Für jeden lexikographischen akzessiven Eintrag gilt das Folgende: Er weist mindestens ein äußeres Zugriffstextelement auf, das meistens initial in der ersten Eintragszeile steht (aber nicht immer, vgl. (7) in Abb. 1) und ein Element einer äußeren Zugriffsstruktur ist. Bei Wörterbuchartikeln in alphabetischen Wörterbüchern heißt das äußere Zugriffstextelement Lemma. Lemmata sind Leitelementträger. Bei nichtalphabetischen Wörterbüchern heißt das äußere Zugriffstextelement Wörterbuchartikeltitel (kurz: Artikeltitel). Artikeltitel sind keine Leitelementträger, sondern Verweisadressenträger; auf sie kann nur registervermittelt zugegriffen werden. Bei allen anderen akzessiven Einträgen liegen als äußere Zugriffstextelemente Eintragseingänge vor, die Binnentexteingang, Einschubeingang, Umtexteingang, Registereingang, Außentexteingang und 
Listeneingang heißen. Eintragseingänge können sprachlich, numerisch oder alphabetisch sein. Alle sprachlichen Eintragseingänge sind zugleich Zeichengestaltangaben. Es gilt weiterhin, dass ein lexikographischer akzessiver Eintrag eine Konstituente eines lexikographischen Teiltextes mit äußerer Teiltextzugriffsstruktur ist, der akzessive lexikographische Daten enthält, und zwar primär akzessive und sekundär akzessive.

\subsubsection{Bauteile und Typen von Registereinträgen}

Im Folgenden betrachten wir anhand der Registerauszüge in Abb. 1 und Abb. 2 die wichtigsten Bauteile von Registereinträgen und unterscheiden verschiedene Typen von akzessiven Registereinträgen (re).

(1)

bischen s. beruhigen

biss(e)1 s. bißchen

Bißgurre, -gurn s. Steit

Bitz s. bißchen, Kerngehäuse

Bitzel s. bißchen

bitzeln s. prickeln

Bitzerl s. bißchen

Bitzler s. prickeln

Bitzgi s. Kerngehäuse

Bitzli s. bißchen

Blache s. Plane

Blag(e) s. Kind

blaken s. Ruß

bläken s. brüllen

blarren s. weinen
(2)

Blase s. Wasserkessel

Blatt s. Fuß

Blatter s. Anschwellung

Blattern s. Pocken

Blätzer s. Narbe

Blaubeere s. Heidelbeere

Blaukabis

Blaukappes $\}$ s. Kohl

Blaukraut

Blech s. reinigen

Blechner

Blechschläger $\}$ s. Klempner

Blechschmied

Bletz(e) s. Narbe

Bloch s. Block
(3)

para-, Para-

-paradies

-pflichtig

-phil

-phob

Pilot-

Plüsch-

Polit-

-politisch

poly-, Poly-

post-

prä-

pro-, Pro-

Problem-
(4)

Paracelsus $\uparrow$ Begriffs- und Bedeutungsprägung

Partikel $\uparrow$ Gesprächswort $\uparrow$ Gradpartikel

Pejoration $\uparrow$ Bedeutungsverschlechterung

Pejorativbildung auch $\uparrow$ Schimpfwort $\uparrow$ Spottname Dichterling · Empfindelei · Emporkömmling · Fatzke · Finsterling · Frömmling · Geizhals · Günstling · hündisch · kindisch · Kriegsgewinnler · Liebelei . Lüstling · Meckerfritze · Ossi · Piefke · Prahlhans. Raffke · Raufbold · Schreihals · Steppke · Trunkenbold · Weibsbild, -person, -stück · Weichling · Wessi. Witzbold · Wühler

Persisch Babuschen . Basar · Bombast · Borax · Derwisch · Diwan · Karawane · Khaki · Kiosk · Limonade ' Paradies - Rochade ' Saffian ' Schach ' Schal Scharlach · Spinat · Taft · Tasse · Tulpe · Turban Zinnober
(5)

$$
\begin{aligned}
& \text { Regiepult } 14.10 \text { Film und Kino } \\
& \text { regierbar } 9.52 \text { Leicht } \\
& \text { regieren } 15.74 \text { Führung; } 18.12 \text { Herr- } \\
& \text { schen } \\
& \text { regierend } 18.12 \text { Herrschen } \\
& \text { Regierung } 15.71 \text { Schicht; } 15.74 \text { Füh- } \\
& \text { rung; } 18.4 \text { Politik; } 18.9 \text { Regierung; } \\
& \quad \text { 18.10 Verwaltungsbehörde; } \\
& \quad \text { 18.12 Herrschen } \\
& \text { Regierungs- } 18.10 \text { Verwaltungsbe- } \\
& \text { hörde }
\end{aligned}
$$


(6)

backen 111

bauen 130

beachten 102

beantworten 106

bearbeiten 109

beauftragen 285

bedanken, sich 171

bedrängen 214

bedrohen 205

beeilen, sich 231

beenden 389

beerben 281
(7)

anziehen (Kleidung)
Anziehsachen
Apfelsine
Appetit
Ar, der
Arbeitspause
ärgern (es ärgert mich)
Arschbacke, die
artig
As(s) (Spielkarte), das
Aschkasten
Aspik
Ass
Ästchen
Atem
atzen
* au Backe!

\author{
$\mathrm{H}$ anlegen \\ H Gewand, Kluft, Montur \\ $\mathrm{H}$ Orange \\ A $\mathrm{H}$ [i] kurz \\ $\mathrm{H}$ Ar, das \\ $\mathrm{H}$ Brotzeit \\ $\mathrm{H}$; das stinkt mir; mir stinkt er \\ $\mathrm{H}$ Arschbacken, der \\ $\mathrm{H}$ brav \\ $\mathrm{H}$ die Ass, Sau \\ $\mathrm{H}$ Aschenschuber \\ A H [i] kurz: Sulz \\ $\mathrm{H} \quad$ Eiß \\ Àst(er)l, Zweigerl \\ Schnaufer(er) \\ $\mathrm{H}$; füttern; futtern, àmmeln \\ auweh zwick!
}

Abb. 1: Registerausschnitte (1) und (2) aus dem nachspanninternen alphabetischen Register in Seibicke (1989) mit dem Registertitel „Register der in den Wörterbuchartikeln erwähnten gemeinsprachlichen und landschaftlichen Ausdrücke"; (1) $=\mathrm{re}_{1}-\mathrm{re}_{15} ;(2)=\mathrm{re}_{16}-\mathrm{re}_{26}$. Registerausschnitt (3) aus dem vorspanninternen reduzierten alphabetischen Register in Duden-10 mit dem Registertitel „Liste der Wortbildungselemente, die in der alphabetischen Stichwortliste erscheinen“; (3) $=\mathrm{re}_{27}-\mathrm{re}_{40}$. Registerausschnitt (4) mit dem Registertitel "Sachregister - Wegweiser zum Wortschatz" aus dem vorspanninternen alphabetischen Register in Paul (2002); (4) $=\mathrm{re}_{41}-\mathrm{re}_{45}$. Registerausschnitt (5) aus dem nachspanninternen alphabetischen Register mit dem Registertitel „Vollständiges alphabetisches Zugriffsregister" in Dornseiff (2004); (5) $=\mathrm{re}_{46}-\mathrm{re}_{52}$. Registerausschnitt (6) aus dem nachspanninternen alphabetischen Register mit dem Registertitel "Alphabetisches Sachregister" in Helbig und Schenkel (1980); (6) $=\mathrm{re}_{53}-\mathrm{re}_{64}$. Registerausschnitt (7) aus dem nachspanninternen alphabetischen Register mit dem Registertitel „Das Umkehrwörterbuch. Einheitsdeutsch Bairisches Deutsch" in Zehetner (1997); re$_{65}-$ re $_{81}$.

Der erste Registereintrag re in $_{1}(1)$ "bischen s. beruhigen“ ist ein vollständiger Registereintrag. Er besteht aus dem (sprachlichen) Registereingang "bischen", mit dem das Verb bischen genannt wird, und der unmittelbar folgenden nichtelementaren Registerangabe „s. beruhigen“. Diese ist eine vollständige Verweisangabe (sensu Wiegand 2002: 186ff), und zwar eine vollständige Registerverweisangabe, weswegen re $e_{1}$ und alle anderen Registereinträge in (1) zum Typ des vollständigen Registereintrags gehören. Die registerinterne vollständige Verweisangabe "s. beruhigen" ist funktional-positional in zwei unmittelbare Teilangaben segmentierbar: Die erste Teilangabe ist die verdichtete Verweisbeziehungsangabe "s.", mit der eine Abkürzung von siehe genannt wird; die zweite Teilangabe ist die Verweisadressenangabe „beruhigen“, mit der die Verweisaußenadresse Iberuhigen! genannt wird, deren Verweisadressenträger das Lemma "beruhigen“" in wa $a_{1}$ in Abb. 2 ist. 
wa $_{1}$ : beruhigen, beschwichtigen: niederdt. umgangssprachlich (jemanden) begöschen; mittel- und süddt. bischen = ,einen weinenden Säugling beruhigen, auf den Armen wiegen`.

wa2:

interimsabschied, interimsaufwar-

tung, interimsbesitzer, interimscondi-

tion, interimseinteilung, interimsunter-

haltung, interimsvermitlung, interims-

verordnung, interimsweise, interimswe-

sen, s. interim 1 .

(8)

Entlehnung $\uparrow$ Bedeutungsentleh-

nung $\uparrow$ Fremdwortverdeutschung

$\uparrow$ Lehnbildung $\uparrow$ Lehnschöpfung

$\uparrow$ Lehnübersetzung $\uparrow$ Lehnüber-

tragung $\uparrow$ Lehnwort $\uparrow$ Mehrfachentlehnung $\uparrow$ Rückentlehnung

$\uparrow$ Scheinentlehnung $\uparrow$ Wortexport

Entzückungswort auch $\uparrow$ Jugendsprache $\uparrow$ Schülersprache $\uparrow$ Studentensprache

Epochenbezeichnung

Ersatzwort $\uparrow$ Fremdwortverdeut-

schung $\uparrow$ Lehnschöpfung $\uparrow$ Lehn-

übersetzung $\uparrow$ Lehnübertragung
(9)

Birkler, Hubertus $\rightarrow$ Ettle, Josef

Birkmoser, Hanni $\rightarrow$ Falk, Hermann

Birkner, Friede $\rightarrow$ Stein, Elfriede

Birkner, Polten $\rightarrow$ Brosowski, Paul

Birmann, Martin $\rightarrow$ Grieder, Martin

Birnitz, A. von $\rightarrow$ Czibulka, Alfons von

Birnitz, Linda $\rightarrow$ Pietzsch, Lina

Biron, Hans $\rightarrow$ Brüstle, Hans

Biron, Ludwig $\rightarrow$ Siegert, Georg

(10)

Leibniz, Gottfried Wilhelm $9^{*}$

Leitelement $32^{*}, 64^{*}$

Leitelementträger $64^{*}$

Lektüreziel, offenes $42^{*}$

Lemmazeichen $64^{*}$

Lemmazeichengestaltangabe $85^{*}$

Lewy, E. 23*

lexikographische Information

s. Information, lexikographische

- Makrostruktur

s. Makrostruktur, lexikographische

- Wörterbuchpflege

s. Wörterbuchpflege, lexikographische

Abb. 2: Wörterbuchartikel (= wa) wa 1 aus Seibicke (1989); verdichteter Verweisartikel wa $_{2}$ aus FWB 8/1; Registerausschnitt (8) aus Paul (2002); (8) = $\mathrm{re}_{82}-\mathrm{re}_{85}$. Registerausschnitt (9) aus Eymer (1997); (9) = re 86 $_{86}-$ re $_{44}$. Registerausschnitt (10) aus dem Register mit dem Registertitel „Register zur lexikographisch-historischen Einführung" in Dornseiff (2004); (10) = re 95 $_{5}-\mathrm{re}_{104}$.

Jeder sprachliche Registereingang ist ein Leitelementträger; d.h. am Beispiel von re $_{1}$ : Das Verb bischen liefert einem Benutzer das Leitelement Ibischenl, mit 
dessen Hilfe er eine Benutzungshandlung vom Typ der externen Registerzugriffshandlung (sensu Wiegand 1998: 472f) ausführen kann, um in der Registerzugriffsstruktur den Registereingang „bischen“ zu finden, der das gleiche Leitelement wie das Verb bischen aufweist. In vollständigen Registereinträgen kann die Verweisbeziehungsangabe auch durch Verweisungspfeile realisiert sein, wie z.B. in (9) in Abb. 2.

Der erste Registereintrag re ${ }_{53}$ in (6) in Abb. 1 "backen 111" ist ein reduzierter Registereintrag: Die registerinterne numerische Verweisangabe „111“, mit der als Außenadresse eine Seitenzahl als Element der äußeren Seitenzahlzugriffsstruktur genannt wird, gehört zu den elementaren reduzierten Verweisangaben (sensu Wiegand 2002: 186ff), die als Teilangaben keine Verweisbeziehungsangaben aufweisen. Reduzierte Verweisangaben (die sich auch in Wörterbuchartikeln finden) bestehen nur aus einer Verweisadressenangabe. Alle reduzierten Registereinträge, mit deren Registerangaben Seitenzahlen oder Spaltenzahlen genannt werden, funktionieren wie eine reduzierte Doppeladressenangabe. Mit der Außenadressenangabe "111" wird die numerische Hauptadresse genannt, die in der Seitenzahlzugriffsstruktur liegt; mit dem Registereingang wird die Unteradresse IbackenI genannt, deren Verweisadressenträger der Artikeltitel backen ist, auf den nur registervermittelt zugegriffen werden kann (da Helbig und Schenkel 1980 ein nichtalphabetisches Wörterbuch ist). Ein Benutzer-in-actu, der anhand des reduzierten Registereintrages „backen 111“ einen Registerverweis (i.S.v. Wiegand 2002: 211ff) erschließt und diesem durch die Ausführung einer Verweisbefolgungshandlung folgt, muss zuerst auf die Hauptadresse, nämlich auf die Seitenzahl 111 zugreifen und kann erst danach die Unteradresse und damit backen auf der Seite 111 erreichen.

Die Registereinträge in (3) in Abb. 1 gehören alle zum Typ des vollständig reduzierten Registereintrags. Registereinträge dieses Typs bestehen nur aus mindestens einem Registereingang. Wie sie funktionieren, wird in Abschnitt 2.2 erklärt.

Nicht mit allen numerischen registerinternen Außenadressenangaben werden Seiten- oder Spaltenzahlen genannt. In dem reduzierten einfachen Registereintrag "csatol 54" aus (23) in Abb. 15 wird mit der numerischen Außenadressenangabe „,54" eine Lemmanummer genannt, da Ildikó (2007) eine alphanumerische makrostrukturelle äußere Doppelzugriffsstruktur aufweist, so dass die Lemmata mit Lemmanummernangaben durchgezählt sind (vgl. Wiegand 2008). In dem reduzierten einfachen Registereintrag "brevitas 0436" aus (24) in Abb. 15 wird mit der numerischen Außenadressenangabe "0436", die in der Zugriffsspalte des tabellarischen Wörterverzeichnisses von Kytzler und Redemund (2007) stehende Zugriffsnummer genannt, die die Artikelblöcke zählt (vgl. Wiegand 2000a).

Im Folgenden betrachten wir re ${ }_{41}$, den ersten Registereintrag in (4), der folgende Form aufweist: „Paracelsus $\uparrow$ Begriffs- und Bedeutungsprägung“. In der Vorbemerkung des Registers mit dem Registertitel „Sachregister — Wegweiser 
zum Wortschatz" heißt es in Paul (2002): ",,'个" verweist auf Stichwörter im Sachregister". Aufgrund dieser Erklärung gehört die durch einen Hochpfeil realisierte Verweisbeziehungsangabe für den kundigen Benutzer zum Typ der adressenidentifizierenden Verweisbeziehungsangabe: Die Verweisadresse wird als eine Adresse kenntlich gemacht, deren Verweisadressenträger ein Registereingang ist, nämlich der Registereingang „Begriffs- und Bedeutungsprägung“. Der Registereintrag re $_{41}$ entspricht einem reinen Verweisartikel. Er gehört daher zum Typ des Registerverweiseintrages, zu dem auch re ${ }_{43}$ aus (4) in Abb. 1 gehört. Sowohl $\mathrm{re}_{41}$ als auch $\mathrm{re}_{43}$ weisen gerade eine vollständige Registerverweisangabe auf. Der Registereintrag re ${ }_{42}$ „Partikel $\uparrow$ Gesprächswort $\uparrow$ Gradpartikel" weist zwei Registerverweisangaben auf. Manche Registerverweiseinträge in Paul (2002) weisen mehr als zehn Registerverweisangaben auf. Es ist daher zweckmäßig, zwischen einfachen und erweiterten Registerverweiseinträgen $\mathrm{zu}$ unterscheiden. Einfache Registerverweiseinträge weisen gerade eine Registerverweisangabe auf (wie $\mathrm{re}_{41}$ und $\mathrm{re}_{43}$ ), erweiterte (wie $\mathrm{re}_{42}$ ) dagegen mindestens zwei.

In dem Registerausschnitt (5) treten nur reduzierte Registereinträge auf. Mit den registerinternen reduzierten Verweisangaben, z.B. mit "9.52 Leicht" aus re 47 ",regierbar 9.52 Leicht", wird gerade eine zweiteilige Verweisadresse genannt. Der Verweisadressenträger ist der Artikeltitel, bestehend aus der Sachgruppennummer "9.52" und dem unmittelbar folgenden Artikeltitel "Leicht" , so dass keine Doppeladresse vorliegt, da Haupt- und Unteradressen im Verweiszielbereich niemals unmittelbar auf einander folgen. In $\mathrm{re}_{48}$, dem Registereintrag mit dem Registereingang „regieren“, werden zwei Verweisadressen genannt, und in re ${ }_{50}$, dem Registereintrag mit dem Registereingang „Regierung", werden sechs Verweisadressen genannt. Es ist daher zweckmäßig, zwischen einfachen und erweiterten reduzierten Registereinträgen zu unterscheiden: Reduzierte Registereinträge, in denen nur eine Verweisadresse genannt wird, gehören zum Typ des einfachen reduzierten Registereintrags. Reduzierte Registereinträge, in denen mindestens zwei Verweisadressen genannt werden gehören dagegen zum Typ des erweiterten reduzierten Registereintrags, wie z.B. $\mathrm{re}_{45}$ in (4) mit dem Registereingang „Persisch“. Eine analoge Unterscheidung ist auch bei den vollständigen Registereinträgen zweckmäßig. Beispielsweise gehört $\mathrm{re}_{4}$ in (1) in Abb. 1, nämlich „Bitz s. bisschen, Kerngehäuse" zum Typ des erweiterten vollständigen Registereintrags, während die anderen Registereinträge in (1) zum Typ des einfachen vollständigen Registereintrags gehören. Anhand von $\mathrm{re}_{4}$ kann man übrigens erkennen, dass man den Unterschied zwischen einfachen und erweiterten Registereinträgen nicht ohne weiteres an der Zahl der Verweisadressenangaben festmachen darf, denn "s. bißchen, Kerngehäuse" hat als Teilangabe eine (nichtelementare) homosegmentäre Verweisadressenangabe, die aus zwei Adressenangaben besteht, so dass mit einer nichtelementaren Adressenangabe zwei Verweisadressen genannt werden. Der Unterschied zwischen einfachen und erweiterten Registereinträgen muss mithin entweder (wie geschehen) an der Zahl der genannten Ver- 
weisadressen oder an der Anzahl der elementaren Verweisadressenangaben festgemacht werden.

Bei allen drei charakterisierten Typen von Registereinträgen, dem Typ des erweiterten vollständigen, und dem des erweiterten reduzierten Registereintrags sowie dem Typ des erweiterten Registerverweiseintrags lassen sich die einfach von den mehrfach erweiterten Einträge unterscheiden. Eine Mehrfacherweiterung liegt dann vor, wenn in einem Registereintrag mindestens drei Verweisadressen genannt werden. Mehrfach erweiterte reduzierte Registereinträge sind re 45 aus (4) mit dem Registereingang „Persisch" und re 50 aus (5) mit dem Registereingang „,Regierung ". Mehrfach erweiterte vollständige Registerverweiseinträge sind z.B. $\mathrm{re}_{82}$ aus (8) in Abb. 2 mit dem Registereingang „Entlehnung" und res5 mit dem Registereingang „Ersatzwort".

In (7) in Abb. 1, dem Registerausschnitt aus Zehetner (1997), treten linkserweiterte Registereinträge auf; die Linkserweiterung ist entweder durch einen Asterisk oder durch zwei realisiert oder durch ", $\ddot{\circ}^{\prime \prime}$. In allen Fällen handelt es sich um eine topikalisierte Registerangabe, die an den Registereingang adjazent rechtsadressiert ist. Mit " $\ddot{\mathrm{o}}^{\prime \prime}$ wird z.B. eine verdichtete Austriazismusidentifizierungsangabe realisiert. Die Registereingänge in (7), die topikalisierte Registerangaben aufweisen, gehören zum Typ des reduzierten Registereintrags mit topikalisierter Registerangabe.

Weiterhin ist unbedingt das Folgende zu beachten: Die Erweiterung und die Reduzierung betreffen nur die mediostrukturellen Eigenschaften und Teile von Registereinträgen und damit auch die Fundortdaten. Es gibt jedoch auch eine Anreicherung von Registereinträgen; diese bezieht sich nicht auf die Fundortdaten, sondern besteht darin, dass Registerangaben auftreten, die keine vollständigen oder reduzierten Verweisangaben sind. In (7) sind alle topikalisierten Registerangaben sowie die gestaltkonstanten Angaben " $\mathrm{A}^{\prime \prime}$, , $\mathrm{B}$ " und " $\mathrm{H}^{\prime \prime}$ keine Verweisangaben, sondern verdichtete Angaben: Mit " $\mathrm{A}$ “ wird z.B. angegeben, dass ein Ausspracheunterschied vorliegt und mit "B", dass ein Unterschied in der Betonung gegeben ist. Registereinträge, die Angaben aufweisen, die keine Fundortangaben sind, heißen angereicherte Registereinträge. Alle Registereinträge in (7) in Abb. 1, die eine der drei topikalisierten Registerangaben aufweisen und/oder eine der beiden Angaben ", $\mathrm{A}^{\prime \prime}$, , $\mathrm{B}$ " und/oder beide Angaben " $\mathrm{A}$ " und " $\mathrm{B}$ " sind angereicherte Registereinträge. Registereinträge mit gerade einer nicht verweisvermittelnden Angabe, wie z.B. " ** au Backe! auweh zwick!" (= re $\left.e_{11}\right)$, sind einfach angereicherte Registereinträge. Registereinträge mit mehreren nichtverweisvermittelnden Angaben, wie z.B. „ö Ass H Eiß" $\left(=\mathrm{re}_{77}\right)$, gehören zum Typ des mehrfach angereicherten Registereintrags. Da eine der nichtverweisvermittelnden Angaben, nämlich "Ӧ“ eine topikalisierte Registerangabe ist, gehört re 77 zum Typ des mehrfach angereicherten Registereintrags mit topikalisierter Registerangabe. Auch erweiterte Registereinträge können zusätzlich angereichert sein, so dass erweiterte und angereicherte Registereinträge vorliegen. - Im Folgenden fassen wir einen Teil der bisherigen Betrachtungen zu den Bauteilen und Eigenschaften von Registereinträgen zu einem Typologieausschnitt zusammen. 


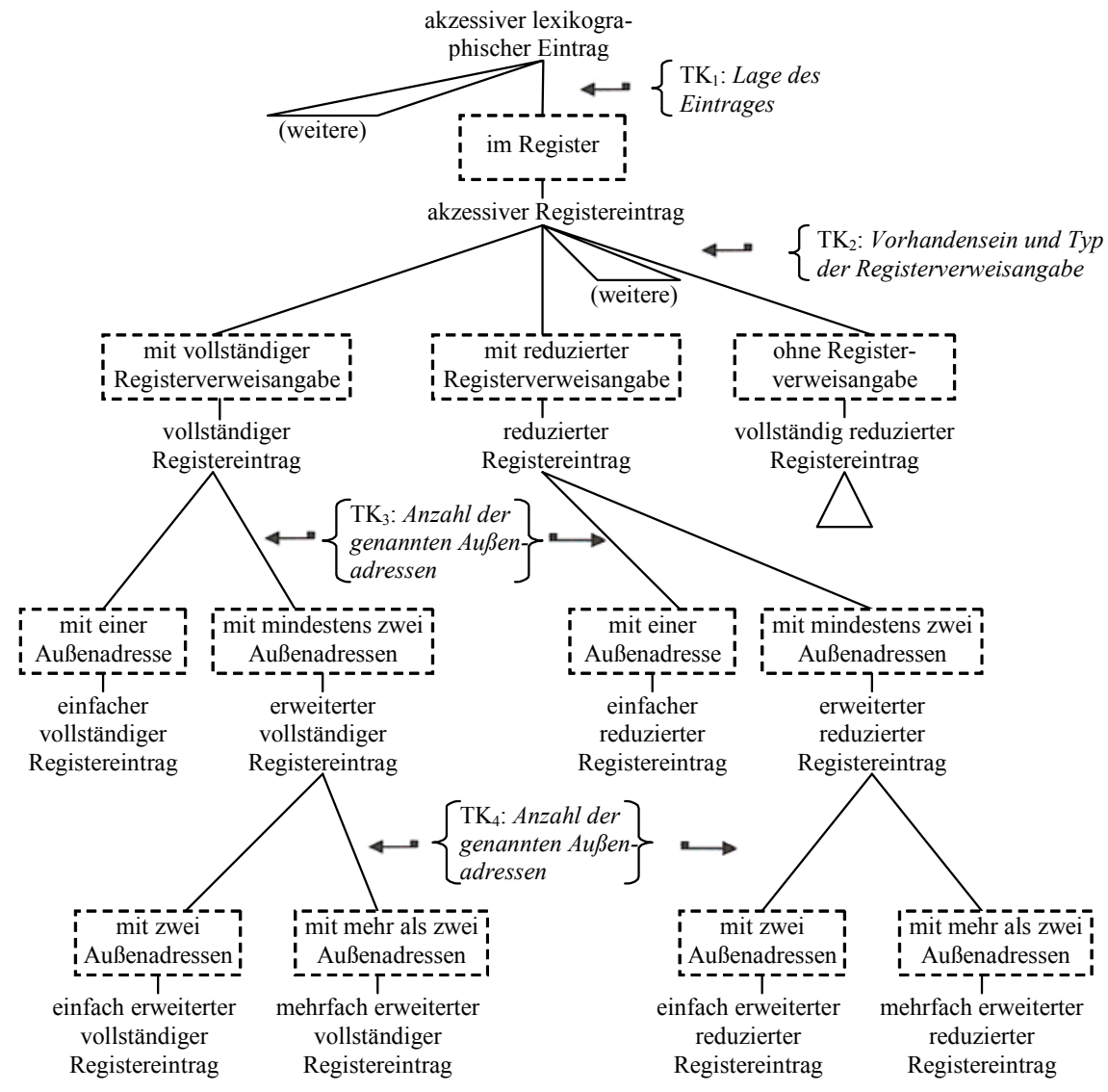

Abb. 3: Erweitert kommentierter Typologiegraph zum ersten Typologieausschnitt aus einer Typologie von Registereinträgen in Printwörterbüchern nach Art und Anzahl der Registerverweisangaben. Abkürzungen: TK = Typologiekriterium;

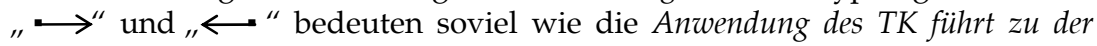
Unterteilung

Von den Definitionen, die zu dem Typologieausschnitt in Abb. 3 gehören, seien die beiden Folgenden genannt:

(D-1: einfacher vollständiger Registereintrag)

Ein einfacher vollständiger Registereintrag ist ein Registereintrag, auf dessen Registereingang genau eine vollständige Registerverweisangabe folgt, deren Außenadressenangabe elementar ist.

(D-2: erweiterter reduzierter Registereintrag)

Ein erweiterter reduzierter Registereintrag ist ein Registereintrag, auf dessen Registereingang mindestens zwei reduzierte Registerverweisangaben folgen. 
Im Folgenden betrachten wir die mediostrukturelle Orientierung der Registerverweisangaben und der zugehörigen Registereinträge. Jedes verweisvermittelnde Textsegment weist eine mediostrukturelle Orientierung auf (vgl. Wiegand 2002: 182ff). Diese wird durch das adressenvermittelnde Textsegment festgelegt, bei Verweisangaben mithin durch die Verweisadressenangabe. Es gibt mehrere Untertypen des Typs der Verweisadressenangabe; der wichtigste Untertyp ist der Typ der Außenadressenangabe. Die vollständige Registerverweisangabe „s. beruhigen" ist lemmatisch orientiert, weil der Verweisadressenträger ein Lemma ist. Statt lemmatisch orientiert sagt man auch artikelorientiert. Ist der Verweisadressenträger ein Artikeltitel, sagt man immer artikelorientiert. Die mediostrukturelle Orientierung eines verweisvermittelnden Textsegmentes vererbt sich auf den akzessiven Eintrag, zu dem das verweisvermittelnde Textsegment gehört. Wird mit dem verweisvermittelnden Textsegment eine Verweisaußenadresse (kurz: Außenadresse) genannt, also eine, die nicht im gleichen akzessiven Eintrag zu finden ist, in dem das verweisvermittelnde Textsegment steht, dann weist das verweisvermittelnde Textsegment eine mediostrukturelle Außenorientierung auf. Wird dagegen mit dem verweisvermittelnden Textsegment eine Verweisbinnenadresse (kurz: Binnenadresse) genannt, also eine, die im gleichen akzessiven Eintrag zu finden ist wie das verweisvermittelnde Textsegment, dann weist das verweisvermittelnde Textsegment eine mediostrukturelle Binnenorientierung auf. Binnenorientierte Registerverweisangaben sind zwar möglich, in meinem empirischen Material jedoch bisher nicht aufgetreten; d.h. registereintragsinterne Verweisung ist derzeit nicht belegbar; registerinterne Verweisung tritt dagegen öfters auf.

Die registerinterne vollständige Verweisangabe „s. beruhigen“ ist lemmatisch und damit außenorientiert. Diese mediostrukturelle Orientierung vererbt sich auf den Registereintrag. Demgemäß ist $\mathrm{re}_{1}=$ „,bischen s. beruhigen“ ein lemmatisch und damit außenorientierter Registereintrag. Da in $\mathrm{re}_{1}$ nur eine Außenadresse genannt wird, ist $\mathrm{re}_{1}$ ein einfach außenorientierter Registereintrag. Ein einfach außenorientierter Registereintrag ist immer monodirektional, so dass gilt: Alle Benutzer, die anhand von re $e_{1}$ einen Verweis erschließen und eine Verweisbefolgungshandlung erfolgreich ausführen, etablieren einen $\mathrm{Zu}$ griffspfad der zum Typ des registerexkurrenten artikeladkurrent orientierten Zugriffspfads (sensu Wiegand 2007: 191ff) gehört und der beim Lemma beruhigen von $\mathrm{wa}_{1}$ (vgl. Abb. 2) endet. Der Registereintrag re ${ }_{4}$ aus (1), nämlich „Bitz s. bisschen, Kerngehäuse" ist mehrfach außenorientiert. Ein mehrfach außenorientierter Registereintrag ist immer polydirektional. Die beiden in $\mathrm{re}_{4}$ genannten Außenadressen sind in der gleichen äußeren Zugriffsstruktur zu finden, nämlich in der makrostrukturellen Hauptzugriffsstruktur von Seibicke (1989). Daher gehört $\mathrm{re}_{4} \mathrm{zu}$ den homogen außenorientierten Registereinträgen: Alle registerexkurrenten Zugriffspfade enden bei der gleichen äußeren Zugriffsstruktur. Der Registereintrag re ${ }_{44}$ aus (4) mit dem Registereingang „Pejorativbildung" ist dagegen heterogen außenorientiert. Denn die Verweisadressenträger, die zu den Außenadressen ISchimpfwortl und |Spottnamel gehören, sind Elemente der alphabetischen Registerzugriffsstruktur und damit Register- 
eingänge, während alle anderen im gleichen Registereintrag genannten Verweisadressen von IDicherling $\mid$ । bis IWühler| als Verweisadressenträger ein Lemma aufweisen; demgemäß ist der Registereintrag re ${ }_{44}$ register- und lem-

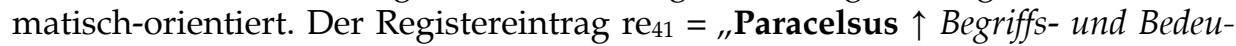
tungsprägung" ist einfach registerorientiert. Der Registereintrag $\mathrm{r}_{44}$ aus (4) in Abb. 1 ist mehrfach registerorientiert. Der Registereintrag re $_{97}=$ "Leitelementträger $64^{*}$ in (10) in Abb. 2 ist einfach umtextorientiert. Der Registereintrag re ${ }_{96}$ $=$ ",Leitelement $32^{*}, 64^{* \prime \prime}$ in (10) ist homogen außenorientiert, und zwar mehrfach umtextorientiert: Die beiden Hauptadressen $\left|32^{*}\right|$ und $\left|64^{*}\right|$ liegen in der Seitenzahlzugriffsstruktur zum Umtext „Lexikographisch-historische Einführung". Der Registereintrag re $\mathrm{r}_{104}=$ „Wörterbuchpflege s. Wörterbuchpflege, lexi-

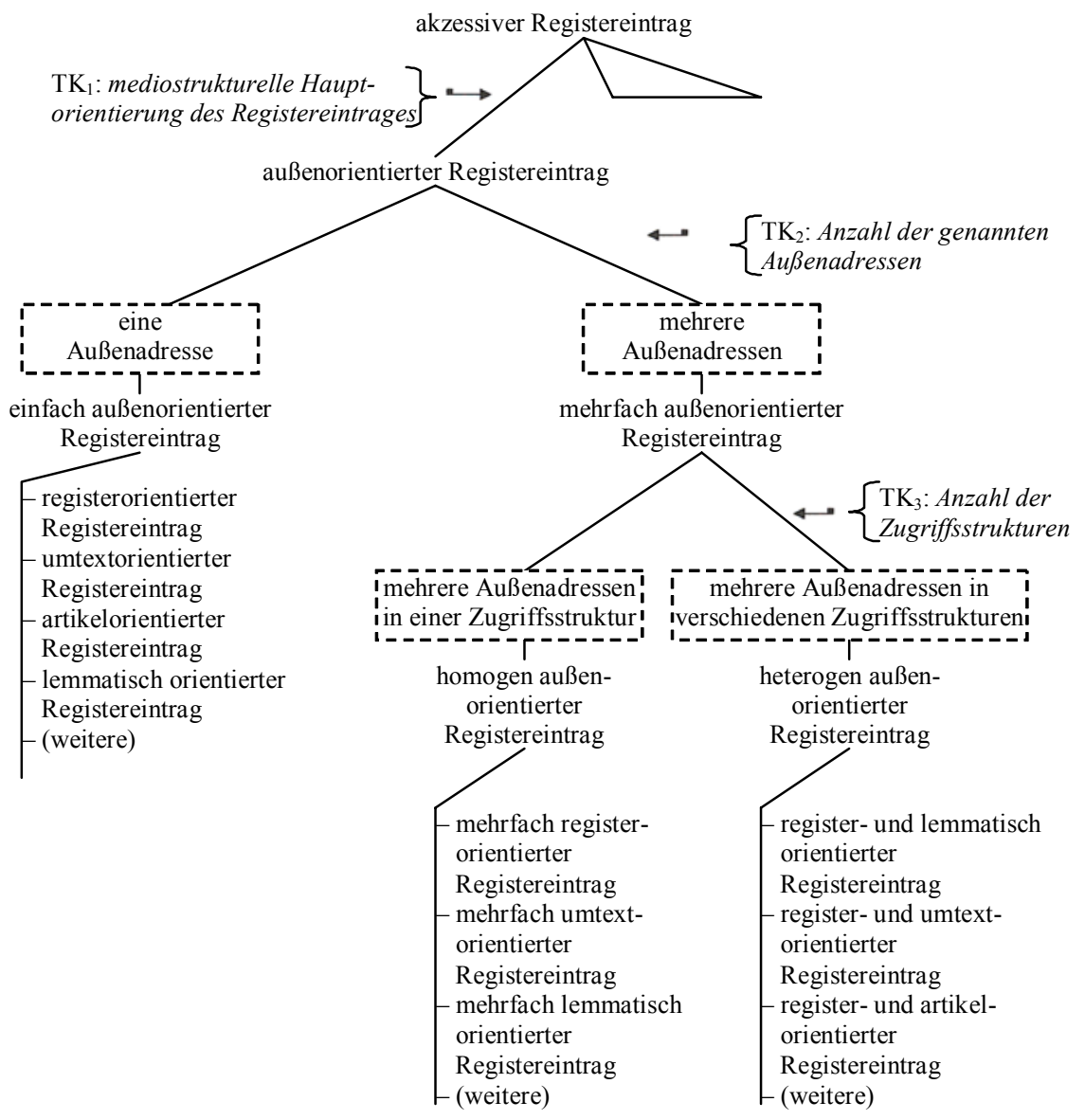

Abb. 4: Partiell erweitert kommentierter Typologiegraph zum zweiten Typologieausschnitt aus einer Typologie von Registereinträgen in Printwörterbüchern nach der Art der mediostrukturellen Orientierung 
kographische" aus (10) in Abb. 2 ist einfach registerorientiert. Die Ausführungen zur mediostrukturellen Orientierung von Registereinträgen werden nachfolgend in einem Typologieausschnitt zusammengefasst.

Von den Definitionen, die zu dem Typologieausschnitt in Abb. 4 gehören, seien die beiden Folgenden genannt:

(D-3: einfach außenorientierter Registereintrag)

Ein einfach außenorientierter Registereintrag ist ein einfacher Registereintrag, mit dessen Registerverweisangabe gerade eine Außenadresse genannt wird.

(D-4: heterogen außenorientierter Registereintrag)

Ein heterogen außenorientierter Registereintrag ist ein erweiterter Registereintrag, mit dessen Registerangaben mindestens zwei Außenadressen genannt werden, die in verschiedenen äußeren $\mathrm{Zu}$ griffsstrukturen liegen.

\subsubsection{Strukturen von Registereinträgen}

Wie die anderen akzessiven Einträge, die aus Angaben bestehen, so weisen auch die Registereinträge - außer den vollständig reduzierten - konkrete hierarchische Strukturen auf, und zwar:

- $\quad$ konkrete hierarchische registerinterne Eintragskonstituentenstrukturen (kurz: registerinterne Konstituentenstrukturen)

- $\quad$ konkrete hierarchische registerinterne Eintragsmikrostrukturen (kurz: registerinterne Mikrostrukturen) und

- $\quad$ konkrete hierarchische registerinterne Eintragsangabenstrukturen (kurz: registerinterne Angabenstrukturen).

$\mathrm{Zu}$ allen genannten Strukturen gehören isomorphe abstrakte hierarchische Strukturen. Weiterhin weisen Registereinträge konkrete nichthierarchische Adressierungsstrukturen auf, $\mathrm{zu}$ denen isomorphe abstrakte angegeben werden können. Im Folgenden werden Beispiele für Registereintragsstrukturen behandelt.

Die meisten Strukturen von Registereinträgen sind wenig komplex. Zahlreiche Register weisen nur dann registerinterne Konstituentenstrukturen auf, wenn die Segmentationskonvention in Kraft gesetzt ist, dass registerinterne Leerzeichen (oder: Blanks) als nichttypographische registerinterne Mikrostrukturanzeiger gelten, so dass in der konkreten registerinternen Konstituentenstruktur Mikrostrukturanzeigerblanks $\left({ }_{\mathrm{i}} \mathrm{MiSB}_{\mathrm{j}}\right.$ ) angesetzt werden können (wie in Abb. 5 (1)). Alle Registereinträge im Registerausschnitt (6) in Abb. 1 weisen z.B. nur dann eine konkrete hierarchische registerinterne Konstituentenstruktur auf, wenn der Blank zwischen Registereingang und numerischer Register- 
angabe als Mikrostrukturanzeigerblank gilt. Die konkrete hierarchische registerinterne Konstituenten- und Mikrostruktur von re ${ }_{53}$ aus (6), dem Registereintrag „backen 111“, sind in Abb. 5 dargestellt.

(1)

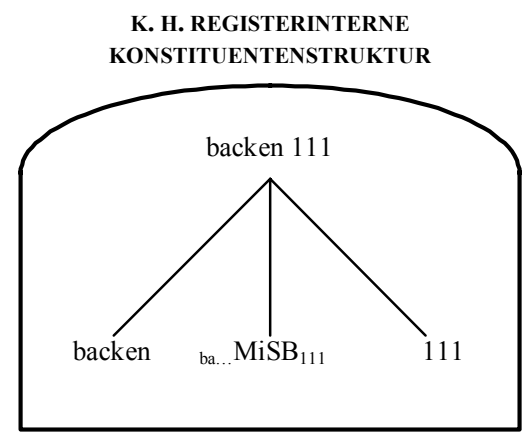

(2)

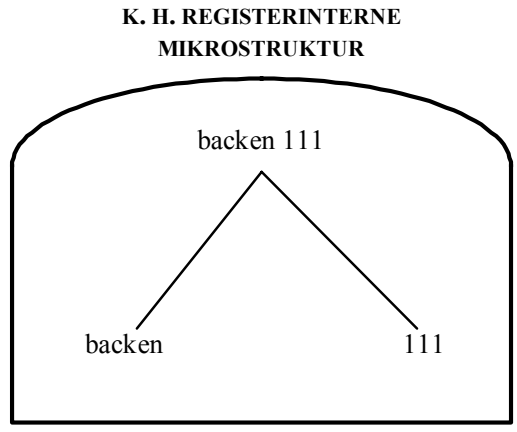

Abb. 5: Kommentierter Strukturgraph zur konkreten hierarchischen registerinternen Konstituentenstruktur des Registereintrags $\mathrm{re}_{53}$ aus (6) in Abb. 1 (1) und zur konkreten hierarchischen registerinternen Mikrostruktur von $\mathrm{re}_{53}(2)$

Methodisch gesehen, sind die registerinternen hierarchischen Strukturen auf die gleiche Weise erhältlichen wie die hierarchischen Artikelstrukturen. Dies sei im Folgenden für die registerinternen erweiterten Mikrostrukturen exem-

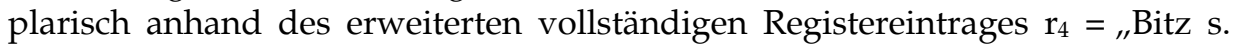
bisschen, Kerngehäuse" aus (1) in Abb. 1 demonstriert. Zuerst wird $r_{4}$ mittels einer Anwendung der Methode der nichtexhaustiv funktionalpositionalen Segmentation (sensu Wiegand 2005a: 217ff) so segmentiert, dass folgende sechs Registereintragskonstituenten gegeben sind:

(a) "Bitz", der Registereingang (REg),

(b) „s. bisschen, Kerngehäuse“, die nichtelementare registerinterne Verweisangabe (VerwA.ri),

(c) "s.", die registerinterne verdichtete Verweisbeziehungsangabe (v.VerwBA.ri),

(d) „bißchen, Kerngehäuse“, die registerinterne homosegmentäre Außenadressenangabe (AuAdA.2ri),

(e) "bißchen", die registerinterne elementare Außenadressenangabe (AuAdA.ri),

(f) „Kerngehäuse“, die registerinterne elementare Außenadressenangabe (AuAdA.ri).

Im Folgenden benutzen wir die Buchstaben $\mathrm{a}-\mathrm{f}$ als Individuennamen für die Registereintragskonstituenten, $\mathrm{re}_{4}$ als Individuenname für den ganzen Registereintrag und bilden die strukturtragende Menge (oder: die Trägermenge) für 
die konkrete $(\mathrm{k})$ hierarchische registerinterne erweiterte Mikrostruktur von re $\mathrm{f}_{4}$; sie heiße $\mathrm{M}_{\mathrm{T}}^{\mathrm{k}}\left(\mathrm{re}_{4}\right)$ und kann wie folgt angegeben werden: $\mathrm{M}_{\mathrm{T}}^{\mathrm{k}}\left(\mathrm{re}_{4}\right)=\{\mathrm{a}, \mathrm{b}, \mathrm{c}, \mathrm{d}$, $\left.\mathrm{e}, \mathrm{f}, \mathrm{re}_{4}\right\}$.

Auf der Menge $\mathrm{M}_{\mathrm{T}}^{\mathrm{k}}\left(\mathrm{re}_{4}\right)$ werden nun zwei ordnungsstrukturprägende Relationen definiert, und zwar die Folgenden:

(1) Eine zweistellige Relation vom Typ der partitiven Relation (oder: TeilGanzes-Relation) - sie heiße $R_{\text {part }}\left(\mathrm{re}_{4}\right)$ - die reflexiv, antisymmetrisch und transitiv ist. $R_{\text {part }}\left(r_{4}\right)$ ist eine Teilmenge des einfachen Kreuzproduktes $\mathrm{M}_{\mathrm{T}}^{\mathrm{k}}\left(\mathrm{re}_{4}\right) \times \mathrm{M}_{\mathrm{T}}^{\mathrm{k}}\left(\mathrm{re}_{4}\right)$. Für das einfache Kreuzprodukt einer Menge $\mathrm{M}$ mit sich selbst wird im Folgenden stets $\mathrm{M}^{2}$ geschrieben; also gilt: $\mathrm{R}_{\text {part }}\left(\mathrm{re}_{4}\right) \subseteq\left(\mathrm{M}_{\mathrm{T}}^{\mathrm{k}}\left(\mathrm{re}_{4}\right)\right)^{2}$. Der Relationsterm $\left(=\mathrm{RT}_{1}\right)$, der $\mathrm{zu} \mathrm{R}_{\text {part }}\left(\mathrm{re}_{4}\right)$ gehört, lautet: $\mathrm{RT}_{1}=x$ ist eine Registereintragskonstituente von $y$, mit $x$ als Variable für Registereintragskonstituenten und $y$ als Variable für Registereinträge, wie z.B. re $e_{4} \cdot \mathrm{RT}_{1}$ spezifiziert aus dem Kreuzprodukt $\left(\mathrm{M}_{\mathrm{T}}^{\mathrm{k}}\left(\mathrm{re}_{4}\right)\right)^{2}$ genau die geordneten Paare, die $\mathrm{zu} \mathrm{R}_{\mathrm{part}}\left(\mathrm{re}_{4}\right)$ gehören, $\mathrm{z} . \mathrm{B}$. die Paare: (a, re 4 ) und (f, $\left.\mathrm{re}_{4}\right)$.

(2) Weiterhin wird auf $\mathrm{M}_{\mathrm{T}}^{\mathrm{k}}\left(\mathrm{re}_{4}\right)$ ein zweistellige Relation vom Typ der Präzedenzrelation (oder: Vorgänger-Nachfolger-Relation) - sie heiße $\mathrm{R}_{\mathrm{p}}\left(\mathrm{re}_{4}\right)$ - definiert; $\mathrm{R}_{\mathrm{p}}\left(\mathrm{re}_{4}\right)$ ist irreflexiv (damit asymmetrisch) und transitiv und zu ihr gehört der Relationsterm $\mathrm{RT}_{2}=x$ geht voraus $y$ mit $x$ und $y$ als Variablen für Registereintragskonstituenten. Es gelten: $\mathrm{R}_{\mathrm{p}}\left(\mathrm{re}_{4}\right) \subseteq$ $\left(\mathrm{M}_{\mathrm{T}}^{\mathrm{k}}\left(\mathrm{re}_{4}\right)\right)^{2} ; \mathrm{R}_{\text {part }}\left(\mathrm{re}_{4}\right) \cap \mathrm{R}_{\mathrm{p}}\left(\mathrm{re}_{4}\right)=\varnothing$. Die Vereinigung von $\mathrm{R}_{\mathrm{part}}\left(\mathrm{re}_{4}\right)$ und $R_{p}\left(r_{4}\right)$, nämlich $R_{\text {part }}\left(\mathrm{re}_{4}\right) \cup R_{\mathrm{p}}\left(\mathrm{re}_{4}\right)$, ordnet den Registereintrag re $\mathrm{re}_{4}$ vollständig. Die registerinterne Eintragsmikrostruktur von $\mathrm{re}_{4}$ ist mithin eine Ordnungsstruktur.

Im nächsten Schritt weisen wir dann die Registereintragskonstituenten ihren Klassen $\mathrm{zu}$, und zwar mittels Aussagen der Form $\lambda \in \beta$ (zu lesen wie $\lambda$ ist ein Element von $\beta$ ). Für „, $\beta^{\prime \prime}$ werden die oben bereits eingeführten Klassensymbole verwendet. Demgemäß ergeben sich folgende Aussagen:

$$
\begin{aligned}
& a \in \text { REg, } \\
& b \in \text { VerwA.ri, } \\
& c \in \text { VerwBA.ri, } \\
& d \in \text { AuAdA'.ri, } \\
& \text { e } \in \text { AuAdA.ri, } \\
& f \in \text { AuAdA.ri. }
\end{aligned}
$$

Als Klassensymbol für die Klasse aller Registereinträge (eines Registers) verwenden wir RE und bilden nun folgende Trägermenge für die abstrakte (a) hierarchische registerinterne erweiterte Mikrostruktur von $\mathrm{re}_{4}$.

$$
\begin{aligned}
\mathrm{M}_{\mathrm{T}}^{\mathrm{a}}\left(\mathrm{re}_{4}\right)= & \{\text { REg, VerwA.ri, v.VerwBA.ri, } \\
& \text { AuAdA².ri, AuAdA.ri, RE }\} .
\end{aligned}
$$


Auf $\mathrm{M}_{\mathrm{T}}^{\mathrm{a}}\left(\mathrm{re}_{4}\right)$ werden nun ebenfalls eine Relation vom Typ der partitiven Relation und eine vom Typ der Präzedenzrelation definiert; diese Operation verläuft analog zu der im Falle der konkreten Struktur und wird daher nicht näher beschrieben.

Wie bei Artikelmikrostrukturen, so erfolgt die Darstellung von registerinternen Eintragsmikrostrukturen mittels geordneter Baumgraphen. In Abb. 3 sind der Baumgraph für die konkrete und der für die abstrakte Struktur zu einem einfach kommentierten Strukturgraphen dadurch zusammengefasst, dass sie aufeinander abgebildet sind. In einem solchen Strukturgraphen sind von der konkreten hierarchischen Eintragsmikrostruktur nur die terminalen mikrostrukturellen Konstituenten direkt wahrnehmbar; die nichtterminalen lassen sich jedoch anhand der vollständig sichtbaren abstrakten Struktur systematisch erschließen.

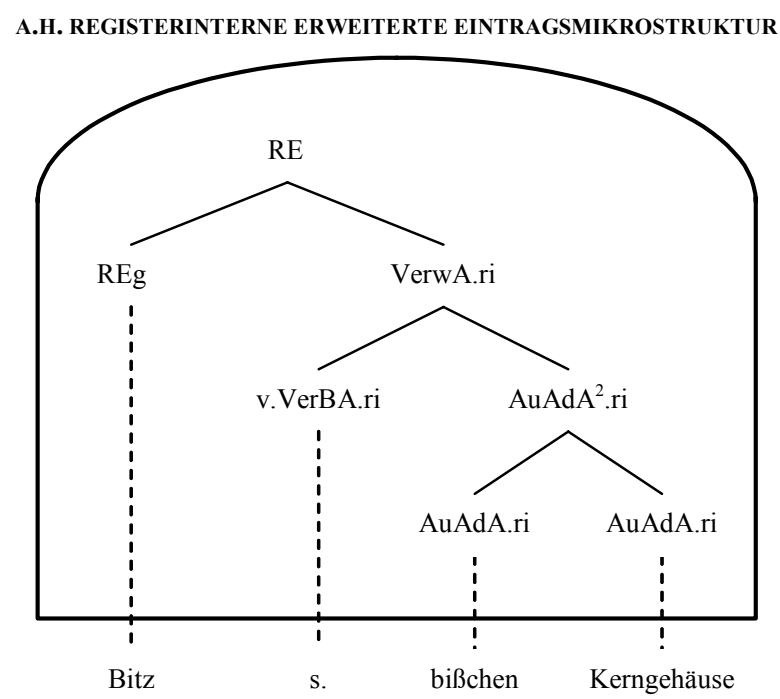

Abb. 6: Einfach kommentierter Strukturgraph zur abstrakten (und isomorphen konkreten) registerinternen erweiterten Mikrostruktur des Registereintrages re $_{4}$ in Abb. 1; "x---y" bedeutet (von unten nach oben gelesen) soviel wie $\mathrm{x} \in \mathrm{y}$; ", $\mathrm{x}-\mathrm{y}$ " bedeutet von (von unten nach oben gelesen) soviel wie $x$ ist eine Registereintragskonstituente von y; Abkürzungen: A = ABSTRAKT; $\mathrm{H}=$ HIERAR$\mathrm{CHISCH}$

In dem Register, aus dem (1) stammt, gibt es nur sehr wenige Registereinträge mit registerinternen homosegmentären Außenadressenangaben, und alle sind nur zweifach homosegmentär. Obwohl dazu in der Registervorbemerkung nichts gesagt wird, sind die elementaren Außenadressenangaben alphabetisch geordnet: "bißchen“ kommt alphabetisch vor „Kerngehäuse“. Auf die alphabe- 
tische Anordnung der registerinternen Außenadressenangaben, die hier bewusst nicht berücksichtigt wurde, wird daher später zurückzukommen sein.

Im Folgenden betrachten wir den kondensierten Registereintrag $\mathrm{r}_{22}$ aus (2) in Abb. 1. Dieser weist die folgende Form auf:

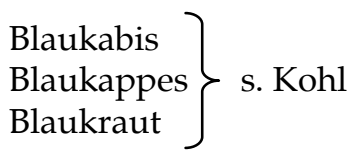

Die exakte Analyse von re 22 erfordert ein relativ elaboriertes Analyseinstrumentarium, das jedoch in der Heuristik, die zur Theorie der Wörterbuchform gehört, vollständig zur Verfügung steht. Zum besseren Verständnis betrachten wir zunächst vergleichend $\mathrm{wa}_{2}$ in Abb. 2. Es handelt sich um einen verdichteten Verweisartikel; dieser kann verstanden werden als sei er im Zuge der äußeren Textverdichtung (sensu Wiegand 1998b: 28ff; vgl. auch Bustos Plaza und Wiegand 2006) aus zehn Verweisartikeln mit zehn gleichlautenden Verweiskommentaren "s. interim 1", die alphabetisch unmittelbar aufeinander folgen, dadurch entstanden, das neun Mal der Verweiskommentar "s. interim 1" getilgt wurde und die Verweislemmata zusammengerückt wurden. Statt die soeben nur grob skizzierte Methode der äußeren Textverdichtung anzuwenden, hätte man auch - wie in $\mathrm{re}_{22}$ - die Methode der akkoladenindizierten Textverdichtung anwenden können, dann hätte das Ergebnis (= wa' $\left.{ }_{2}\right)$ wie folgt ausgesehen:

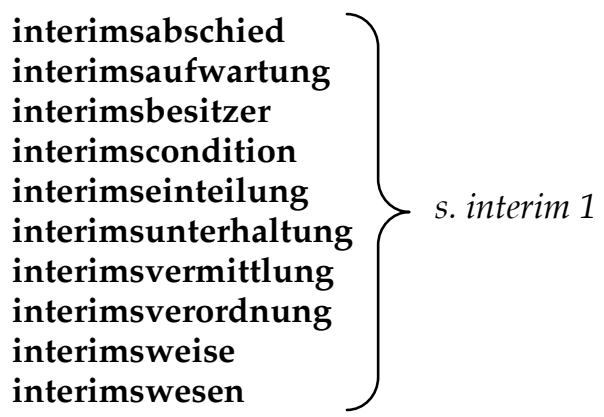

Der verdichtete Verweisartikel $\mathrm{wa}_{2}$ in Abb. 2 ist mit wa' ${ }_{2}$ funktionsgleich; $\mathrm{wa}_{2}$ und wa'2 sind jedoch strukturell verschieden. Während wa 2 eine (reine) Artikelkonstituentenstruktur aufweist und als deren Teilstruktur eine (reine) Artikelmikrostruktur, weist wa' ${ }_{2}$ eine textuelle Struktur auf, die zu keinem der beiden Artikelstrukturtypen gehört. Mit Hinblick auf die Makrostruktur findet sich in $\mathrm{wa}_{2}$ ein Lemmacluster vom Typ des alphabetischen Verweislemmaclusters, das aus zehn Verweislemmata besteht. Mit Hinsicht auf die Artikelmikrostruktur liegt eine homosegmentäre Lemmazeichengestaltangabe vor, die aus zehn Lemmazeichengestaltangaben besteht (LZGA $\left.{ }^{10}\right)$. In wa' ${ }_{2}$ findet sich ein alphabetisches Verweislemmacluster mit den gleichen zehn Verweislemmata. Während jedoch in wa $\mathrm{a}_{2}$ auf der Menge aller clusterzugehörigen Lemmata nur 
eine Relation vom Typ der striktinitialalphabetischen Relation definiert ist (mit dem Relationsterm $\mathrm{RT}_{3}=x$ geht $y$ striktinitialalphabetisch voraus, mit $x$ und $y$ als Variablen für Lemmata), ist in wa' 2 auf der gleichen Lemmatamenge zusätzlich eine textarchitektonische Relation vom Ty der oberhalb-Relation definiert (mit dem Relationsterm $\mathrm{RT}_{4}=x$ ist oberhalb von $y$, mit $x$ und $y$ als Variable für Lemmata).

Betrachtet man nun vergleichend $\mathrm{re}_{22}$, dann gilt, dass $\mathrm{re}_{22}$ auch folgende Form aufweisen könnte:

$\mathrm{r}_{22}^{\prime}=$ Blaukabis, Blaukappes, Blaukraut s. Kohl.

$\mathrm{r}_{22}$ und $\mathrm{r}_{22}^{\prime}$ sind funktionsgleich aber strukturell verschieden. Während $\mathrm{r}_{22}$ eine konkrete und isomorphe abstrakte registerinterne Mikrostruktur aufweist, die Teilstrukturen der registerinternen konkreten und isomorphen abstrakten registerinternen Eintragskonstituentenstruktur sind, weist $r_{22}$ keine textuellen Strukturen dieses Typs auf. Vielmehr ist die Struktur, die $\mathrm{r}_{22}$ aufweist vom gleichen Typ wie die, die zu wa' 2 gehört.

Die Frage ist also nun: $\mathrm{Zu}$ welchem Strukturtyp gehört die textuelle Struktur von $\mathrm{r}_{22}$ ? Um diese Frage angemessen beantworten zu können, muss zuerst die Schweifklammer betrachtet werden. Es handelt sich im buchwissenschaftlichen Sinn um den hinteren Teil einer Akkolade. Eine Akkolade ist eine Schweifklammer ",....", mit der (beschriebene) Zeilen zu einer Menge von (beschriebenen) Zeilen, die unmittelbar übereinander liegen, zusammengeordnet werden. Dies kann, wie in $\mathrm{r}_{22}$, auch nur mit dem hinteren Teil einer Akkolade ", " erfolgen. ", ' besitzt eine linksgerichtete Klammeröffnung und eine rechte Klammerspitze. Im metalexikographischer Sprechweise handelt es sich um den hinteren Teil eines Zusammenordnungszeichens (hZOZ), das zugleich eine Textkondensierung anzeigt. , ," ist damit ein nichttypographischer Kondensations- und Konstituentenstrukturanzeiger. Bei dem Registereintrag $\mathrm{re}_{22}$ in Abb. 1 (2) handelt es sich um einen Registereintrag mit einem Eingangscluster und akkoladenindizierter Textverdichtung. Die zugehörigen konkreten (und abstrakten isomorphen) Konstituentenstrukturen gehören zum Typ der hierarchischen zweiteiligen registerinternen Konstituentenstruktur mit vertikalarchitektonisch ausgebauter linker Teilstruktur. Konstituentenstrukturen dieses Typs weisen im Unterschied zu den allermeisten Artikelkonstituentenstrukturen als Teilstrukturen keine Mikrostrukturen auf. Der Grund dafür ist, dass in den Trägermengen von Mikrostrukturen (welcher Art auch immer) weder nichttypographische Strukturanzeiger noch Klassen solcher Strukturanzeiger enthalten sein dürfen. Eine angemessene Darstellung der textuellen Struktur von re $_{22}$ ist jedoch ohne Berücksichtigung der Schweifklammer nicht möglich.

Im Folgenden wird die textuelle abstrakte Struktur, die von re ${ }_{22}$ zuerst in Abb. 7 dargestellt und daraufhin erläutert, wie sie erhältlich ist.

Im Folgenden wird grob erläutert, wie die in Abb. 7 dargestellte abstrakte Struktur, die zu re 22 gehört, auf methodische Weise erhältlich ist. Zunächst wird 


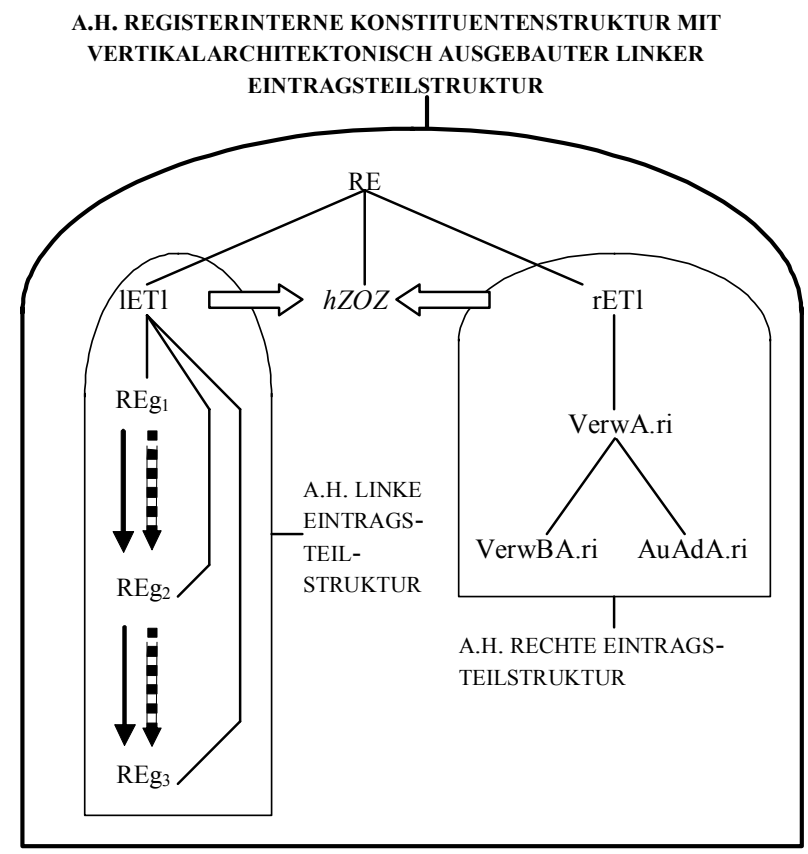

Abb. 7: Kommentierter mit architektonischen Komponenten angereicherter Strukturgraph zur abstrakten hierarchischen zweiteiligen registerinternen Konstituentenstruktur mit vertikalarchitektonisch ausgebauter linker Teilstruktur; " $\mathrm{x}-\mathrm{y}$ " bedeutet (von unten nach oben gelesen) soviel wie $x$ ist ein Teil von $y$; " $\mathrm{u} \Longrightarrow \mathrm{v}$ " bedeutet soviel wie $u$ ist oberhalb von $v,{ }_{,} \rightarrow \mathrm{s}^{\prime \prime}$ bedeutet soviel wie $r$ geht $s$ alphabetisch voraus; $\mathrm{a} \Rightarrow \mathrm{b}$ bedeutet soviel wie $a$ ist links von $b ; \mathrm{b} \Leftarrow \mathrm{c}$ bedeutet soviel wie $c$ ist rechts von $b ; \mathrm{a} \Leftrightarrow \mathrm{b}$ bedeutet soviel wie $a$ ist links von $b$ und $b$ ist rechts von a. Abkürzungen: $\mathrm{RE}=$ Registereintrag; $1 \mathrm{ETl}=$ linker Eintragsteil; rETl = rechter Eintragsteil; $h \mathrm{ZOZ}$ = hinteres Zusammenordnungszeichen

im ersten Schritt $\mathrm{re}_{22}$ durch eine Anwendung der Methode der erweiterten exhaustiven funktional-positionalen Segmentation segmentiert. Diese Methodenvariante lässt $\mathrm{zu}$, dass eine Menge klassengleicher Angaben und Textsegmente, die im Text unmittelbar übereinander stehen, als genau eine nichtelementare Textkonstituente gilt, so dass das folgende Segmentationsergebnis mit drei Registerkonstituenten gegeben ist (rk):

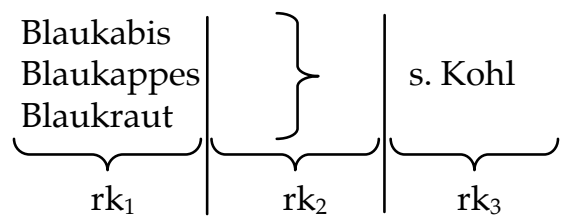


Im zweiten Schritt wird $\mathrm{rk}_{1}$ in die drei Registereingänge reg ${ }_{1}=$ "Blaukabis", $\operatorname{reg}_{2}={ }_{\text {"Blaukappes" }}$ und reg $_{3}={ }_{\text {"Blaukraut }}$ "segmentiert. Im dritten Schritt wird die registerinterne Außenadressenangabe "s. Kohl" (= i) in "s.", die verdichtete Verweisbeziehungsangabe $(=\mathrm{j})$ und in "Kohl", die Außenadressenangabe $(=\mathrm{k})$, segmentiert. Dann werden im vierten Schritt die ermittelten Textsegmente wie folgt ihren Klassen zugeordnet: $\mathrm{rk}_{1} ; \in \mathrm{lETl}$; $\mathrm{rk}_{2} \in h \mathrm{ZOZ}$ : reg $\mathrm{r}_{1} \in$ $\operatorname{Reg}_{1} ; \operatorname{reg}_{2} \in \mathrm{REg}_{2} ; \mathrm{reg}_{3} \in \mathrm{REg}_{3} ; \mathrm{rk}_{3} \in \mathrm{rETl} ; \mathrm{i} \in \mathrm{VerwA.ri} ; \mathrm{j} \in \mathrm{v}$.VerwBA.ri; $\mathrm{k} \in$ AuAdA.ri.

Im fünften Schritt wird die Trägermenge für die abstrakte hierarchische registerinterne Konstituentenstruktur mit vertikalarchitektonisch ausgebauter linker Eintragsteilstruktur - sie heiße $\mathrm{M}_{\mathrm{T}}^{\mathrm{a}}\left(\mathrm{re}_{22}\right)$ - gebildet: $\mathrm{M}_{\mathrm{T}}^{\mathrm{a}}\left(\mathrm{re}_{22}\right)$ kann wie folgt angegeben werden:

$$
\begin{aligned}
& \mathrm{M}_{\mathrm{T}}^{\mathrm{a}}\left(\mathrm{re}_{22}\right)=\left\{\mathrm{RE}, 1 \mathrm{ETl}, h Z \mathrm{ZOZ}, \mathrm{rETl}, \mathrm{REg}_{1}, \mathrm{REg}_{2}, \mathrm{REg}_{3},\right. \text { VerwA.ri, v.Verw. } \\
& \text { BA.ri, AuAdA.ri }\} .
\end{aligned}
$$

In den nächsten sechs Schritten werden dann auf $\mathrm{M}_{\mathrm{T}}^{\mathrm{a}}\left(\mathrm{re}_{22}\right)$ sechs strukturprägende Relationen definiert, und zwar die Folgenden:

(1) Eine Relation vom Typ der partitiven Relation; sie heiße $\mathrm{R}_{\mathrm{part}}^{\mathrm{a}}\left(\mathrm{re}_{22}\right)$; es gilt: $\mathrm{R}_{\text {part }}^{\mathrm{a}}\left(\mathrm{re}_{22}\right) \subseteq\left(\mathrm{M}_{\mathrm{T}}^{\mathrm{a}}\left(\mathrm{re}_{22}\right)\right)^{2}$. Der Relationsterm lautet: $x$ ist ein Teil von $y$ (mit $x$ und $y$ als Variablen für Textsegmentklassen).

(2) Eine Relation vom Typ der Präzedenzrelation; sie heiße $\mathrm{R}_{\mathrm{p}}^{\mathrm{a}}\left(\mathrm{re}_{22}\right)$; es gilt: $\mathrm{R}_{\mathrm{p}}^{\mathrm{a}}\left(\mathrm{re}_{22}\right) \subseteq\left(\mathrm{M}_{\mathrm{T}}^{\mathrm{a}}\left(\mathrm{re}_{22}\right)\right)^{2}$. Der Relationsterm lautet: $x$ geht $y$ voraus (mit $x$ und $y$ als Variablen für Angabeklassen).

(3) Eine Relation vom Typ der oberhalb-Relation; sie heiße $\mathrm{R}_{\mathrm{ob}}^{\mathrm{a}}\left(\mathrm{re}_{22}\right)$; es gilt: $\mathrm{R}_{\mathrm{ob}}^{\mathrm{a}}\left(\mathrm{re}_{22}\right) \subseteq\left(\mathrm{M}_{\mathrm{T}}^{\mathrm{a}}\left(\mathrm{re}_{22}\right)\right)^{2}$. Der Relationsterm lautet: $u$ ist oberhalb von $v$ (mit $u$ und $v$ als Variablen für Klassen von Registereingängen).

(4) Eine Relation vom Typ der links-von-Relation; sie heiße $\mathrm{R}_{\mathrm{lv}}^{\mathrm{a}}\left(\mathrm{re}_{22}\right)$; es gilt: $\mathrm{R}_{\mathrm{lv}}^{\mathrm{a}}\left(\mathrm{re}_{22}\right) \subseteq\left(\mathrm{M}_{\mathrm{T}}^{\mathrm{a}}\left(\mathrm{re}_{22}\right)\right)^{2}$. Der Relationsterm lautet: $r$ ist links von $v$ (mit $r$ und $v$ als Variablen für Klassen von unmittelbaren Textkonstituenten des Registereintrags).

(5) Eine Relation vom Typ der rechts-von-Relation; sie heiße $\mathrm{R}_{\mathrm{rv}}^{\mathrm{a}}$ ( $\mathrm{re}_{22}$ ); es gilt: $\mathrm{R}_{\mathrm{rv}}^{\mathrm{a}}\left(\mathrm{re}_{22}\right) \subseteq\left(\mathrm{M}_{\mathrm{T}}^{\mathrm{a}}\left(\mathrm{re}_{22}\right)\right)^{2}$. Der Relationsterm lautet: $v$ ist rechts von $r$ (mit $v$ und $r$ als Variablen für Klassen von unmittelbaren Textkonstituenten des Registereintrags. $\mathrm{R}_{\mathrm{lv}}^{\mathrm{a}}\left(\mathrm{re}_{22}\right)$ und $\mathrm{R}_{\mathrm{rv}}^{\mathrm{a}}\left(\mathrm{re}_{22}\right)$ sind konvers.

(6) Eine Relation vom Typ der alphabetischen Relation; sie heiße $\mathrm{R}_{\mathrm{al}}^{\mathrm{a}}\left(\mathrm{re}_{22}\right)$; es gilt: $\mathrm{R}_{\mathrm{al}}^{\mathrm{a}}\left(\mathrm{re}_{22}\right) \subseteq\left(\mathrm{M}_{\mathrm{T}}^{\mathrm{a}}\left(\mathrm{re}_{22}\right)\right)^{2}$. Der Relationsterm lautet: $u$ geht $v$ alphabetisch voraus (mit $u$ und $v$ als Variablen für Klassen von Registereingängen).

Alle sechs auf $\mathrm{M}_{\mathrm{T}}^{\mathrm{a}}\left(\mathrm{re}_{22}\right)$ definierten Relationen sind disjunkt.

In zahlreichen mehrfach erweiterten reduzierten Registereinträgen sind die reduzierten Registerverweisangaben alphabetisch geordnet, wie z.B. in re ${ }_{45}$, 
dem Registereintrag mit dem Registereingang „Persisch“ aus (4) in Abb. 1, oder den Registereinträgen $\mathrm{re}_{105}-\mathrm{re}_{107}$ in (11) in Abb. 8.

(11)

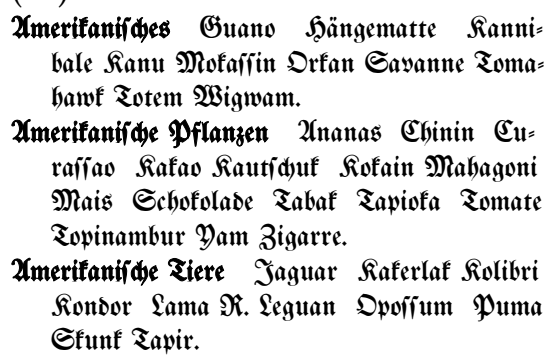
bale $\mathfrak{K a n u}$ Mofarifin Drfan Gayanne Toma hawe $\mathfrak{T}$ otem $\mathfrak{B}$ igwam.

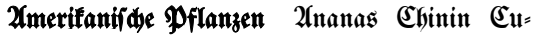

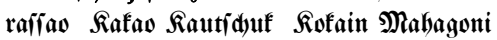
Mais Gibufolade Tabaf Tapiofa Tomate Topinambur Y)am Bigarre.

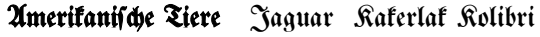
Kondor $\mathfrak{a m a} \Re$. Seguan Dpoffum $\mathfrak{P u m a}$ Sfunf Tapir.

\section{(13)}

Wahnsinnige, der 41,2 347,23

$$
\text { 931,7 }
$$$$
\text { wahr } 55,36119,33 \quad 125,1
$$

$127,54152,34190,11,205,38$

$\begin{array}{lllll}127,54 & 152,34 & 190,11 & 205,38\end{array}$

$\begin{array}{llllll}228,28 & 269,30,286,5 & 427,59\end{array}$

$\begin{array}{llll}482,15 & 509,28 & 561,46 & 571,42\end{array}$

$\begin{array}{llllll}571,43 & 651,45 & 653,47 & 667,28\end{array}$

$687,4721,26 \quad 846,26 \quad 891,12$

$\begin{array}{llll}927,5 & 966,25 & 966,34 & 989,3\end{array}$

$\begin{array}{lll}997,53 & 1008,40 & 1015,37\end{array}$

$1063,31096.19$

Wahre, das 63,19 65,56 71,39

$\begin{array}{llll}96,52 & 111,25 & 119,33 & 168,48\end{array}$

$\begin{array}{lllll}174,43 & 176,3 & 177,63 & 192,22\end{array}$

$\begin{array}{lllll}192,26 & 192,34 & 192,49 & 267,50\end{array}$

$\begin{array}{lllll}269,31 & 399,12 & 413,40 & 418,32\end{array}$

$\begin{array}{lllllllll}423,60 & 425,31 & 426,64 & 428,36\end{array}$

$544,7 \quad 547,28 \quad 549,20 \quad 551,5$

$573,18 \quad 634,49658,8670,42$

$\begin{aligned} & 573,18 \\ & 680,51\end{aligned} 681,496568,8 \quad 670,42$

$680,51681,36 \quad 686,48 \quad 711,60$

$\begin{array}{lllll}715,44 & 746,50 & 749,15 & 787,19\end{array}$

$796,14810,45 \quad 827,6$ 914,

$\begin{array}{llll}1004,40 & 1045,19 & 1047,37\end{array}$

$1061,56 \quad 1062,58 \quad 1065,13$

Wahre, der 668,47
(12)

\begin{tabular}{|c|c|c|}
\hline grassieren & splat & $1571 \mathrm{~V}$ \\
\hline gratis & lat & $1558 \mathrm{Adv}$ \\
\hline Gratulant $\rightarrow$ gratulieren & (lat) & 1743 No M \\
\hline Gratulation $\rightarrow$ gratulieren & lat & 1571 No F \\
\hline ulieren & lat & $1563 \mathrm{~V}$ \\
\hline gravieren & frz & $1787 \mathrm{~V}$ \\
\hline Gravität $\rightarrow$ gravitätisch & lat & 1759 No F \\
\hline ravitätisch & $\mathrm{dt}$ & 1561 A \\
\hline azie $\quad($ frz,engl) & (lat) & 1759 No F \\
\hline ziös $\rightarrow$ Grazie & frz & $1700 \mathrm{~A}$ \\
\hline enadier & frz & 1698 No M \\
\hline
\end{tabular}

(14)

abwehren aab-were

abweiden aab-etze

$\sim$, mühsam nàgle ${ }^{2}$

$\sim$ lassen aab-etze

abweisen aab-wise

$\sim$ (Bitte) ab-schlàà

$\sim$, barsch aab-pùtze

$\sim$, elegant abschüfele,

abschüssele

abweisend ùwéegg

Abb. 8: Registerausschnitt (11) aus Kluge (1943); (11) = $\mathrm{re}_{105}-\mathrm{re}_{107}$; Registerausschnitt (12) aus Kirkness (1988); (12) $=\mathrm{re}_{108}-\mathrm{re}_{118}$. Registerausschnitt (13) aus Dobel (1972); (13) $=\mathrm{re}_{119}-\mathrm{re}_{123}$. Registerausschnitt (14) aus Bratschi und Trüb (1991); $(14)=\mathrm{re}_{124}-\mathrm{re}_{132}$.

Auch in mehrfach erweiterten vollständigen Registereinträgen, wie z.B. re $_{82}$ in (8) in Abb. 2 mit dem Registereingang „Entlehnung“, können die vollständigen Registerangaben alphabetisch geordnet sein. Die Registereinträge $\mathrm{re}_{82}$ und $\mathrm{re}_{105}$ gehören zum Typ des Registereintrages mit alphabetischer innerer Zugriffsstruktur. Registereinträge dieses Typs weisen eine konkrete hierarchische Mikrostruktur mit alphabetischer innerer Zugriffsstruktur auf, zu der eine isomorphe abstrakte angegeben werden kann. In Abb. 9 sind diese dargestellt. 


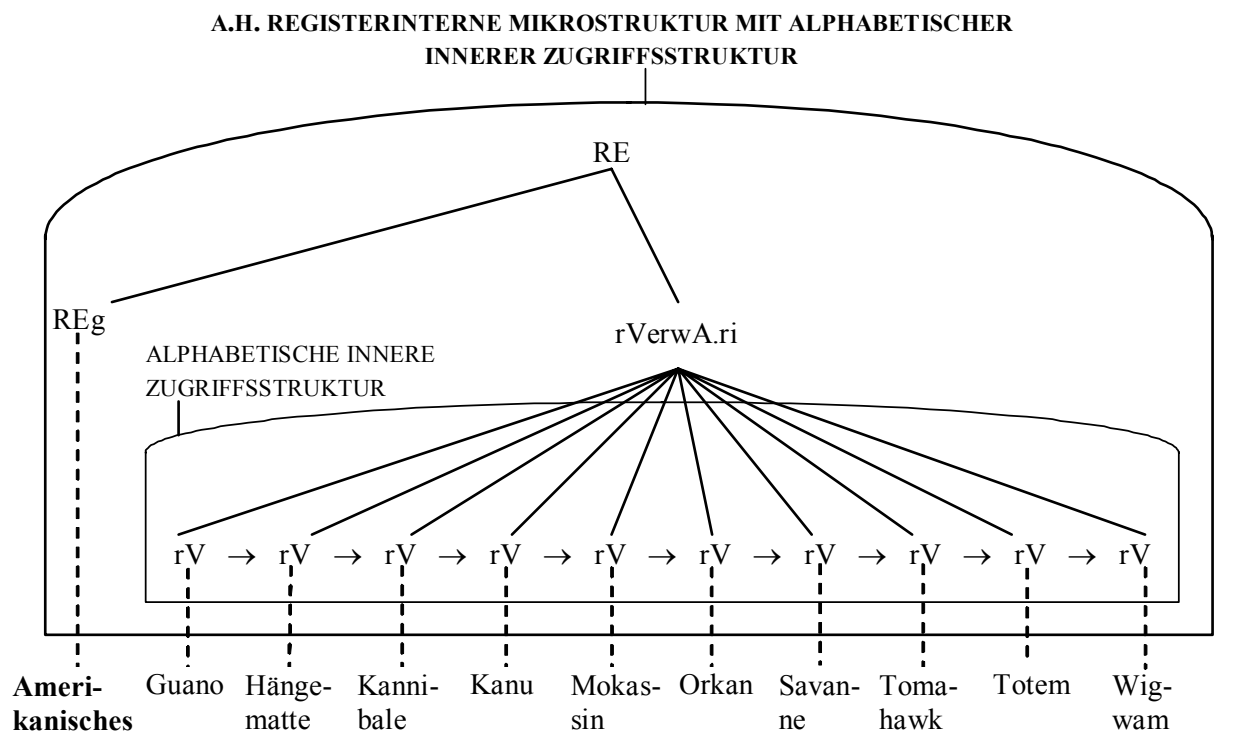

Abb. 9: Kommentierter Strukturgraph zur konkreten (und isomorphen abstrakten) hierarchischen registerinternen Mikrostruktur mit alphabetischer innerer Zugriffsstruktur, die $\mathrm{re}_{105}$ aus (11) in Abb. 8 aufweist. Abkürzungen: rV $=$ rVerwA.ri $=$ registerinterne reduzierte Verweisangabe; " $x \rightarrow y$ " bedeutet soviel wie $x$ geht $y$ striktinitialalphabetisch voraus

Auf der Trägermenge einer hierarchischen registerinternen Mikrostruktur mit alphabetischer innerer Zugriffsstruktur ist neben einer Relation vom Typ der partitiven Relation und einer Relation vom Typ der Präzedenzrelation eine Relation vom Typ der striktinitialalphabetischen Relation definiert mit dem Relationsterm $x$ geht $y$ striktinitial-alphabetisch voraus (mit $x$ und $y$ als Variablen für registerinterne reduzierte Verweisangaben). Die Präzedenzrelation wird benötigt, weil der Registereingang (in $\mathrm{re}_{105}=$ Amerikanisches) der homosegmentären registerinternen reduzierten Verweisangabe nicht striktinitialalphabetisch vorausgeht; vielmehr geht er ihr voraus.

Im Registerausschnitt (13) in Abb. 8 weisen alle erweiterten reduzierten Registereinträge eine numerische innere Zugriffsstruktur auf. Die numerischen reduzierten Registerverweisangaben (z.B. „55, 36") sind geordnete Paare, die aus einer registerinternen Spaltenzahlangabe $\left(, 155^{\prime \prime}\right)$ und einer registerinternen Zeilenzahlangabe $\left(, 36^{\prime \prime}\right)$ bestehen. Spaltenzahlangaben heißen auch Spaltenangaben und Zeilenzahlangaben auch Zeilenangaben. Die konkrete (und isomorphe abstrakte) hierarchische registerinterne Mikrostruktur mit numerischer innerer Zugriffsstruktur, die re $e_{19}$ aus (13) in Abb. 8 aufweist, ist in Abb. 10 dargestellt.

Auf den Trägermengen von registerinternen Mikrostrukturen mit numerischen inneren Zugriffsstrukturen sind neben partitiven und Präzedenzrelationen kleiner-als-Relationen definiert. Registereinträge mit numerischen redu- 
zierten Verweisangaben, die als Teilangaben eine Spaltenangabe und eine Zeilenangabe aufweisen, funktionieren für den Benutzer dann, wenn das Wörterbuch neben einer äußeren Spaltenzahlzugriffsstruktur, auf jeder Wörterbuchseite nachgeordnete Zeilenzahlzugriffsstrukturen aufweist. Dies ist in Dobel (1972) der Fall: Zu jeder der 1144 Spalten gibt es genau eine Zeilenzahlzugriffsstruktur $\langle 10,20,30,40,50,60\rangle$, auf deren numerischen Zugriffstextelementen eine oberhalb-Relation definiert ist, so dass auf jedem Außen- und Innensteg der Wörterbuchseite eine gleichartige senkrechte Zeilenzahlzugriffsstruktur verläuft, die dem Benutzer einen zeilengenauen Zugriff ermöglicht.

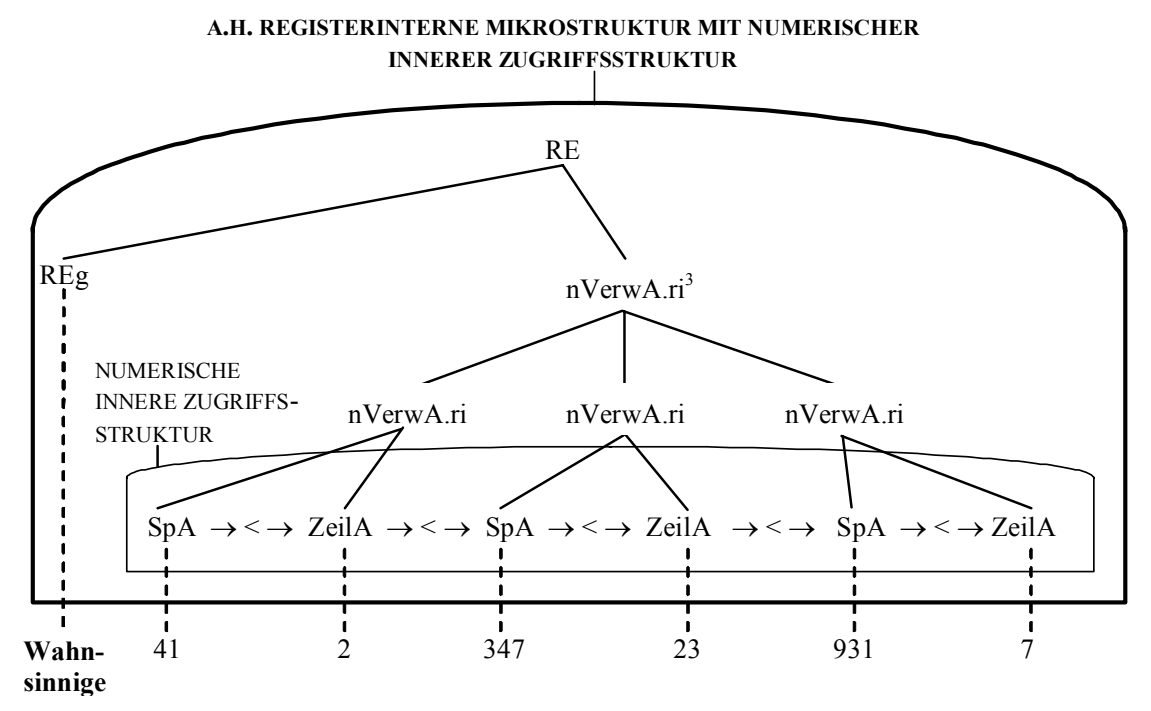

Abb. 10: Kommentierter Strukturgraph zur konkreten (und isomorphen abstrakten) registerinternen Mikrostruktur mit numerischer innerer Zugriffsstruktur, die re $_{119}$ aus (13) in Abb. 8 aufweist: Abkürzungen: SpA = Spaltenangabe; ZeilA =Zeilenangabe; nVerwA.ri = registerinterne numerische Verweisangabe; , $x \rightarrow<\rightarrow y$ " bedeutet soviel wie $x$ ist kleiner als $y$

Im Folgenden betrachten wir die Registereinträge in (12). Der Registerausschnitt (12) stammt aus dem alphabetischen Register von Kirkness (1988). Das zugehörige mehrbändige Deutsche Fremdwörterbuch ist nicht striktalphabetisch geordnet, so dass nicht alle Lemmata über die Hauptzugriffsstruktur erreichbar sind. Diejenigen Lemmata, auf die nicht direkt über die Hauptzugriffsstruktur zugegriffen werden kann, werden mit den Registereingängen genannt, auf die eine vollständige Verweisangabe folgt: z.B. „Gratulant $\rightarrow$ gratulieren" in re $e_{110}$ in (12) in Abb. 8. Alle Registereinträge aus (12), in denen auf den Registereingang keine vollständige Verweisangabe folgt, also z.B. "grassieren" und "gratis" können als verweisvermittelnde Registereingänge gelten. In 
Abb. 11 wird die konkrete (und isomorphe abstrakte) hierarchische Registermikrostruktur von re $\mathrm{e}_{17}$ aus (12) in Abb. 8 dargestellt.

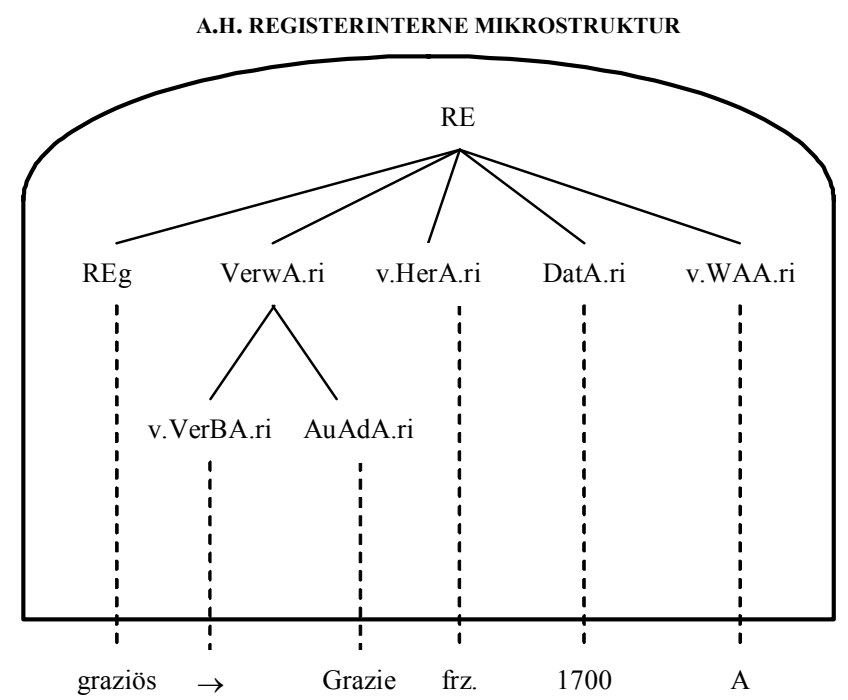

Abb. 11: Kommentierter Strukturgraph zur konkreten (und isomorphen abstrakten) registerinternen Mikrostruktur, die re ${ }_{117}$ aus (12) in Abb. 8 aufweist. Abkürzungen: v.HerA.ri = verdichtete registerinterne Herkunftsangabe; DatA.ri $=$ registerinterne Datierungsangabe; v.WAA.ri = verdichtete registerinterne Wortartangabe; $\mathrm{A}=$ Adjektiv; frz = französisch

Im Registerausschnitt (14) in Abb. 8 sind die Registereinträge, die mit einer Tilde beginnen, wie z.B. re $\mathrm{r}_{130}={ }_{\text {, }}$, , barsch aab-pùtze", Registersubeinträge mit Registersubeingängen. Ein Benutzer-in-actu muss, wenn er den Registersubeintrag (oder: Registeruntereintrag) verstehen möchte, die Tilde durch den vorausgehenden Registereingang ersetzen.

Wie in kondensierten Wörterbuchartikeln oder auch in anderen lexikographischen akzessiven Einträgen, die kondensiert sind und Angaben aufweisen, so treten auch in Registereinträgen Angabenadressierungsbeziehungen auf, in denen Registerangaben zu ihren Bezugsadressen stehen. Bei der Informationsgewinnung muss der Benutzer die adressierten Registerangaben auf ihre Bezugsadressen beziehen (vgl. Wiegand 2000; 2002a; 2006a).

Im Folgenden betrachten wir re $\mathrm{e}_{124}$ aus (12) in Abb. 8. Dieser Registereintrag weist folgende adressierte Angaben auf:

- $\quad$ "splat", die verdichtete registerinterne Herkunftsangabe (v.HerA.ri), mit der eine Abkürzung von spätlateinisch genannt wird.

_ 1571", die Datierungsangabe (DatA.ri) 
- $\quad{ } \mathrm{V}^{\prime \prime}$, die verdichtete Wortangabe (v.WAA.ri), mit der eine Abkürzung vom Verb genannt wird.

Alle drei Angaben sind an den Registereingang "grassieren" linksadressiert, so dass in $\mathrm{re}_{124}$ die Adressierungskonstellation der vollständigen Registereingangsadressierung vorliegt. $\mathrm{Zu}$ allen akzessiven Einträgen, in denen adressierte Angaben auftreten, kann eine konkrete Adressierungsstruktur angegeben werden sowie eine zugehörige isomorphe abstrakte.

Im Folgenden wird die abstrakte Adressierungsstruktur angegeben, die zu $\mathrm{re}_{124}$ gehört. Dazu wird zunächst eine Trägermenge für die abstrakte Registereintragsadressierungsstruktur - sie heiße $\mathrm{M}_{\mathrm{REAdS}}^{\mathrm{a}}\left(\mathrm{re}_{124}\right)$ - gebildet; diese muss die Klassen aller adressierten Registerangaben enthalten sowie die Klasse der bezugsadressentragenden Registereingänge. $\mathrm{M}_{\text {REAds }}^{\mathrm{a}}\left(\mathrm{re}_{124}\right)$ kann demgemäß wie folgt angegeben werden:

$$
\mathrm{M}_{\text {REAdS }}^{\mathrm{a}}\left(\mathrm{re}_{224}\right)=\{\mathrm{REg} \text {, v.HerA.ri, DatA.ri, v.WAA.ri }\} \text {. }
$$

Auf dieser Trägermenge wird eine zweistellige asymmetrische und irreflexive Relation - sie heiße $\mathrm{R}_{\mathrm{REAdS}}^{\mathrm{a}}\left(\mathrm{re}_{124}\right)$ - definiert. Es gilt $\mathrm{R}_{\mathrm{REAdS}}^{\mathrm{a}}\left(\mathrm{re}_{124}\right) \subseteq \mathrm{M}_{\mathrm{REAdS}}^{\mathrm{a}}$ $\left(\mathrm{re}_{124}\right)^{2}$. Der Relationstyp ist festgelegt durch den Relationsterm $x$ ist eingangsintern adressiert an y (mit $x$ als Variable für adressierte Registerangaben und $y$ als Variable für bezugsadressentragende Registereingänge). Die strukturprägende Relation $\mathrm{R}_{\mathrm{REAdS}}^{\mathrm{a}}\left(\mathrm{re}_{124}\right)$ induziert auf der Trägermenge $\mathrm{M}_{\mathrm{REAdS}}^{\mathrm{a}}$ $\left(\mathrm{re}_{124}\right)$ eine Partition $\mathrm{P}\left(\mathrm{re}_{124}\right)$; das bedeutet, dass $\mathrm{R}_{\mathrm{REAdS}}^{\mathrm{a}}\left(\mathrm{re}_{124}\right)$ die Trägermenge in zwei disjunkte Teilmengen zerlegt, nämlich in $\mathrm{M}_{\text {KadRA }}^{\mathrm{a}}\left(\mathrm{re}_{124}\right)$, die Menge der Klassen (K) der adressierten (ad) Registerangaben (RA), und in $\mathrm{M}_{\text {KbezREg }}^{\mathrm{a}}\left(\mathrm{re}_{124}\right)$, die Menge der Klassen (K) der bezugsadressentragenden (bez) Registereingänge (REg). $\mathrm{P}\left(\mathrm{re}_{124}\right)$ ist demgemäß wie folgt definiert: $\mathrm{P}\left(\mathrm{re}_{124}\right)$ : $=\left\{\mathrm{M}_{\mathrm{KadRA}}^{\mathrm{a}}\left(\mathrm{re}_{124}\right)\right.$, $\left.\mathrm{M}_{\text {KbezREg }}^{\mathrm{a}}\left(\mathrm{re}_{124}\right)\right\} . \mathrm{M}_{\text {KadRA }}^{\mathrm{a}}\left(\mathrm{r}_{124}\right)$ ist der Vorbereich, $\mathrm{M}_{\text {KbezREg }}^{\mathrm{a}}\left(\mathrm{r}_{124}\right)$ ist der Nachbereich von $\mathrm{R}_{\mathrm{REAdS}}^{\mathrm{a}}\left(\mathrm{re}_{124}\right)$. Die konkrete Adressierungsstruktur, die zu dem Registereintrag re $\mathbf{1}_{24}$ gehört, ist erhältlich, indem man eine Trägermenge bildet, $\mathrm{zu}$ der alle adressierten Registerangaben von re ${ }_{124}$ sowie der bezugsadressentragende Registereingang gehören und danach analog zur Bildung der abstrakten Struktur vorgeht. In Abb. 12 ist die abstrakte vollständig eingangsfokussierte Adressierungsstruktur (1) sowie die isomorphe konkrete vollständig eingangsfokussierte Adressierungsstruktur (2) von re ${ }_{124}$ dargestellt.

Im Registereintrag re ${ }_{124}$ aus (12) in Abb. 8, nämlich „Gravität $\rightarrow$ gravitätisch lat $1561 \mathrm{~A}^{\prime \prime}$ tritt, wie auch in re $\mathrm{e}_{110}$, $\mathrm{re}_{111}$ und re $\mathrm{r}_{17}$ aus (12), eine vollständige Verweisangabe auf, die aus zwei Teilangaben besteht, nämlich aus einer durch den Rechtspfeil $" \rightarrow$ “ realisierten Verweisbeziehungsangabe und der Außenadressenangabe "gravitätisch". Die erste Teilangabe ist an die zweite adjazent rechtsadressiert, so dass in re ${ }_{124}$ die Adressierungskonstellation der partiellen Eingangsadressierung vorliegt. Zu Registereinträgen mit partieller Eingangsadressierung gehören Adressierungsstrukturen vom Typ der registerinternen partiell eingangsfokussierten Adressierungsstruktur. 
(1)

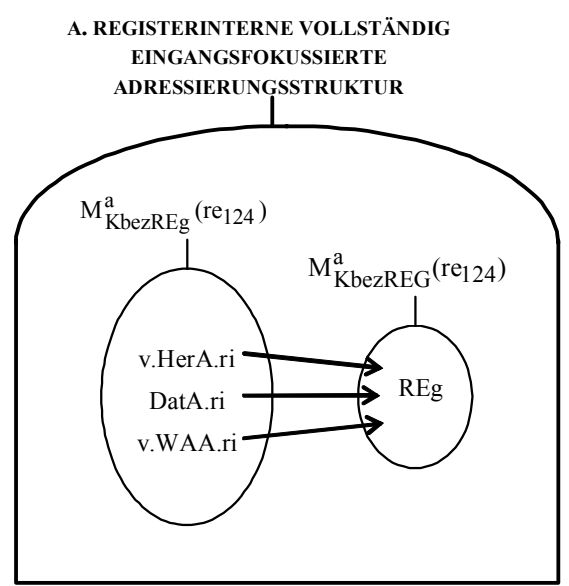

(2)

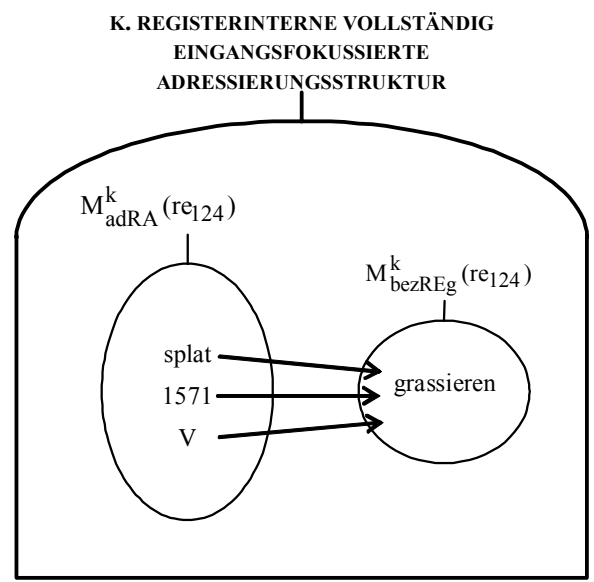

Abb. 12: Kommentierter Strukturgraph zur abstrakten (1) und zur isomorphen konkreten (2) registerinternen vollständig eingangsfokussierten Adressierungsstruktur, die $\mathrm{re}_{124}$ in (12) in Abb. 8 aufweist: Abkürzungen: $\mathrm{A}=\mathrm{ABSTRAKT}$; $\mathrm{K}$ $=$ KONKRET; $\mathrm{M}_{\text {KadRA }}^{\mathrm{a}}\left(\mathrm{re}_{124}\right)=$ Menge der konkreten $(\mathrm{k})$ adressierten (ad) Registerangaben (RA) von re $\mathrm{r}_{124} ; \mathrm{M}_{\mathrm{KbezREg}}^{\mathrm{a}}\left(\mathrm{re}_{124}\right)=$ Menge der konkreten (k) bezugsadressentragende (bez) Registereingänge (REg) von re ${ }_{124}$

Wenn man die registerinternen Mikrostrukturen eines Registereintrages um die zugehörenden Adressierungsstrukturen erweitert, sind die Angabenstrukturen dieses Registereintrages erhältlich. Die Erweiterung erfolgt so, dass auf den Trägermengen für beide Mikrostrukturen, neben den beiden mikrostrukturprägenden Relationen vom Typ der partitiven und der Präzedenzrelation, zusätzlich eine Relation vom Typ der Adressierungsrelation auf beiden Trägermengen definiert wird. Definiert man auf den Trägermengen der in Abb. 11 dargestellten konkreten (und isomorphen abstrakten) hierarchischen registerinternen Mikrostruktur von re 117 zusätzlich eine Relation vom Typ der Adressierungsrelation, sind die konkrete (und isomorphe abstrakte) hierarchische registerinterne Angabenstruktur von re 117 erhältlich.

Für deren Darstellung gibt es zwei Möglichkeiten. Entweder man reichert den Baumgraphen, mit dem die Mikrostruktur dargestellt wird um Pfeile an, die von einem Knoten, der eine adressierte Angabe repräsentiert, zu einem Knoten führt, der die bezugsadressentragende Angabe (und damit auch die Bezugsadresse) repräsentiert, oder man erweitert das Knotenetikett für eine adressierte Angabe um das Adressensymbol hinter dem Mittenpunkt, aus dem ersichtlich ist, welches Textsegment der Bezugsadressenträger ist (z.B. v.HerA.ri $\bullet$ REg). In Abb. 13, in der die konkrete (und isomorphe abstrakte) hierarchische registerinterne Angabenstruktur des Registereintrages re $\mathrm{e}_{17}$ dargestellt ist, wurde das zuerst erläuterte Darstellungsverfahren gewählt. 


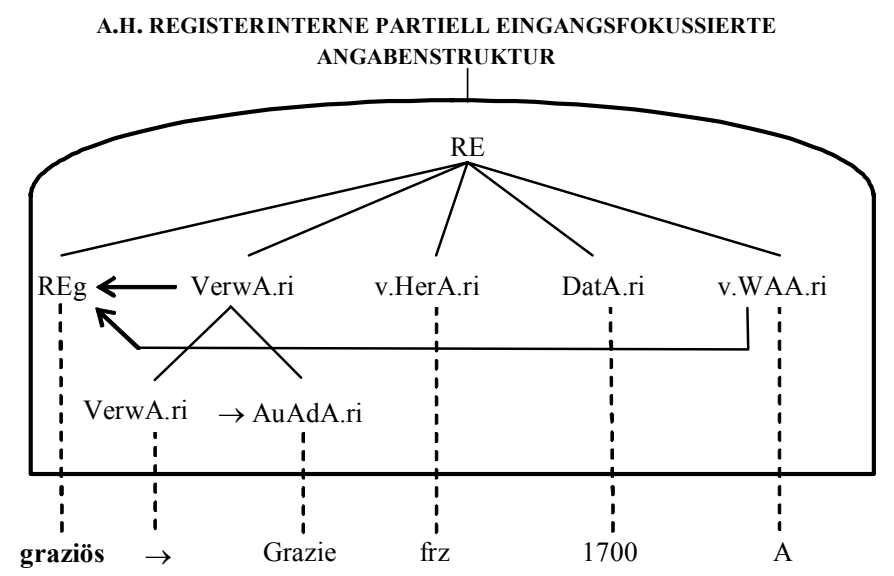

Abb. 13: Kommentierter Strukturgraph zur abstrakten (und konkreten isomorphen) hierarchischen registerinternen partiell eingangsfokussierten Angabenstruktur, die der Registereintrag re ${ }_{117}$ aus (12) in Abb. 8 aufweist; " $\mathrm{x} \rightarrow \mathrm{y}^{\prime \prime}$ bedeutet soviel wie $x$ ist an $y$ adressiert

Damit sind alle in Registereinträgen ausgeprägte Typen von Registereintragsstrukturen exemplarisch behandelt.

\subsection{Typen von Registerzugriffsstrukturen und Typen von Registern}

Jedes Wörterbuchregister weist eine Registerzugriffsstruktur auf. Registerzugriffsstrukturen sind immer äußere Zugriffsstrukturen (vgl. Wiegand 2008). Wörterbuchteile, die Register heißen, aber keine äußere Zugriffsstruktur aufweisen, gelten nicht als Register im Sinne der hier vorgelegten Theorie. Solche Fälle sind selten; ein Beispiel ist das so genannte onomasiologische Register in Scheuplein-Fritz, König, Krämer-Neubert und Wolf (1996, 183-204; vgl. (17) in Abb. 14). Auf dieses "Register" ohne Registerzugriffsstruktur ist ein externer Zugriff nicht möglich. Wer etwas sucht, muss das Register durchlesen! Dass auch onomasiologische Register mit Registerzugriffsstrukturen angelegt werden können, zeigt das Sachregister in Heinzmann (1993).

Registerzugriffsstrukturen heißen wegen der angestrebten deutlichen Unterscheidung $\mathrm{zu}$ allen registerexternen Zugriffsstrukturen auch registerinterne Zugriffsstrukturen. Jedes Wörterbuchregister weist für seine Registerzugriffsstruktur einen direkten Registerzugriffsbereich (kurz: Zugriffsbereich) auf. Der direkte Registerzugriffsbereich ist die Menge aller akzessiven Registereinträge, die aus Registereingängen und Registerangaben bestehen, die meistens auf die Registereingänge folgen, wie man z.B. in den Registerausschnitten (1) bis (6) in Abb. 1 sehen kann. In seltenen Fällen können die Registerangaben auch den Registereingängen vorausgehen, wie z.B. in dem Rückläufigen Register von Kirkness (1988; vgl. (18) in Abb. 14). In manchen Fällen können die Registeran- 
gaben auf die linken Registereingänge folgen und zusätzlich den rechten Registereingängen einer zweiten Registerzugriffsstruktur vorausgehen, wie z.B. in (15) in Abb. 14, einem Ausschnitt aus einem Häufigkeitsregister mit dem Registertitel „Rangliste der Stichwörter" in Erk (1972).

(15)

\begin{tabular}{|c|c|c|c|}
\hline & & D & $\mathrm{F}$ \\
\hline & tun & 30 & 124 \\
\hline 50 & gehen & 31 & 123 \\
\hline & entscheiden & 31 & 120 \\
\hline & sogenannt- & 32 & 117 \\
\hline & unterscheiden & 31 & \\
\hline & erhalten & 31 & 116 \\
\hline & betrachten & 30 & 108 \\
\hline & auftreten & 27 & 107 \\
\hline & bringen & 33 & 106 \\
\hline & stellen & 30 & 102 \\
\hline & erreichen & 28 & 101 \\
\hline 60 & nehmen & 30 & \\
\hline & gewinnen & 27 & 98 \\
\hline & erklären & 29 & 97 \\
\hline & halten & 31 & 96 \\
\hline
\end{tabular}

(17)

Wärme-, Lichtquelle

Trockenstangen am Ofen: Deise (3);

Fackeldeise; Herdstange; Ofendeise;

Ofengestänge; Rick (2); Spändeise

Kerze: Gollicht; Kienlicht; Licht

Docht: Dolich

Brenzelig riechen: brandeln; brandig; räuchern; schmecken, nach Rauch; stinken (2)

Feuer / Kerze anzünden: anstecken;

Feuer machen

Ofen anschüren: anstecken

Feuer im Ofen / Herd erhalten: anlegen

(2); hineinlegen

Elektrisches Licht: anbrennen (2);

andrehen (2); anknipsen

\section{Essen und Trinken}

Frühstuck: Kaffeetrinken (1); Morgenkaffee

Zwischenmahlzeit am Vormittag: Neunuhr

Zwischenmahlzeit am Nachmittag:

Kaffeetrinken (2); Vieruhr (2)
(16)

\begin{tabular}{|c|c|}
\hline Ländername & Staatsbezeichnung \\
\hline Südafrika & Republik Südafrika 232 \\
\hline Sudan & Republik Sudan 233 \\
\hline Südkorea & $\uparrow$ Korea/Republik Korea 141 \\
\hline Suriname & Republik Suriname 234 \\
\hline Swasiland & Königreich Swasiland 235 \\
\hline Syrien & Syrische Arabische Republik 236 \\
\hline Tansania & Vereinigte Republik Tansania 237 \\
\hline Thailand & Königreich Thailand 238 \\
\hline Togo & Togolesische Republik 240 \\
\hline Tonga & Königreich Tonga 241 \\
\hline
\end{tabular}

(18)

$\begin{array}{lllr}\text { No M } & 1689 & \text { dt } & \text { Summarist } \\ \text { No M } & 1718 & \text { dt } & \text { Seminarist } \\ \text { No M } & 1884 & \text { dt } & \text { Utilitarist } \\ \text { No M } & 1927 & \text { dt } & \text { Unitarist } \\ \text { No M } & 1775 & \text { frz } & \text { Aquilibrist } \\ & & & \text { Equilibrist } \\ \text { No M } & 1460 & \text { (mlat) } & \text { Sacrist } \\ \text { No M } & 1750 & & \text { Hypochondrist }\end{array}$

(19)

$\begin{array}{llrl}\text { 11.Jh. } & \text { evangelisch } 1 & \text { lat } & \text { A } \\ & \text { Quader } 1 & \text { lat } & \text { No M F } \\ 1150 & \text { Synode } & \text { mlat,lat } & \text { No F } \\ & \text { Zepter } & \text { (lat,mlat) (griech) } & \text { No N M } \\ 1170 & \text { Sekte } & \text { mlat,lat } & \text { No F } \\ 1177 & \text { Vasall } & \text { (frz?) mlat } & \text { No M } \\ 1195 & \text { Revier 1 } & \text { afrz } & \text { No N }\end{array}$


(20)

\begin{tabular}{|c|c|c|c|}
\hline \multicolumn{4}{|l|}{ Ägyptisch } \\
\hline Pharo & (ägypt) & 1728 & No N \\
\hline \multicolumn{4}{|l|}{ Algonkin } \\
\hline Wigwam & (engl) (algonkin) & 1697 & No M \\
\hline \multicolumn{4}{|l|}{ Arabisch } \\
\hline Algebra & (lat) arab & 1636 & No F \\
\hline Atlas I & arab & 15.Jh. & No M \\
\hline Gazelle & (ital) arab & 1611 & No F \\
\hline Harem & $a r a b$ & 1779 & No M \\
\hline Mameluck & (ital) arab & 1519 & No M \\
\hline Moschee & (frz,span) arab & 1535 & No F \\
\hline Mumie & (pers,arab) & 1534 & No F \\
\hline Natron & (span) arab & 1530 & No N \\
\hline Ottomane 1 & (arab) & 1695 & No F \\
\hline Scheich & $a r a b$ & 1654 & No M \\
\hline Talisman & (span?,ital?) arab & 1646 & No M \\
\hline Tarif & (frz,ital) arab & 1514 & No M \\
\hline Zenit & $(a r a b)$ & 1490 & No M \\
\hline Ziffer & (arab) & 1399 & No F \\
\hline \multicolumn{4}{|l|}{ Babylonisch } \\
\hline Nimrod & 16. Jh. & No M & \\
\hline
\end{tabular}

Abb. 14: Registerausschnitt (15) aus dem nachspanninternen Häufigkeitsregister mit dem Registertitel „Rangliste der Stichwörter"; $(15)=\mathrm{re}_{133}-\mathrm{re}_{148}$. Registerausschnitt (16) aus Herzog und Hannes (1990); (16) = re $\mathrm{r}_{149}-\mathrm{re}_{159}$. Registerausschnitt (17) aus Scheuplein-Fritz, König, Krämer-Neubert und Wolf (1996); (17): ohne akzessive Registereinträge. Registerausschnitt (18) aus Kirkness (1988); (18) = re ${ }_{160}-\mathrm{re}_{167}$; Registerausschnitt (19) aus dem chronologischen Register in Kirkness (1988); (19) $=\mathrm{re}_{168}-\mathrm{re}_{175}$. Registerausschnitt (20) aus dem Herkunftsregister in Kirkness (1988) (20) $=\mathrm{re}_{176}-\mathrm{re}_{196}$

Das Register, aus dem (15) in Abb. 14 stammt, weist eine linke (oder: linkslaufende) und eine rechte (oder: rechtslaufende) numerische Registerzugriffsstruktur auf. Von der linken sind nur die numerischen Registereingänge ",50" und "60" zu sehen. Sie ist gedacht für den externen Zugriff mit Fragen vom Typ: WELCHE VERBEN HABEN DEN RANGLISTENPLATZ X-Y? Die rechte Zugriffsstruktur ist gedacht für Fragen nach der Frequenz im Korpus, die von einer Frequenzzahl ausgehen. Die Registerangaben sind die Verbangaben und die Distributionsangaben. Diese stehen somit vor und nach einem Registereingang.

Register, in deren Registereinträgen nicht mindestens eine Registerverweisangabe auftritt, weisen nur einen direkten Zugriffsbereich auf. Solche Register gehören zum Typ des nichtmediostrukturellen Registers und ihre Registerzugriffsstruktur gehört entsprechend zum Typ der nichtmediostrukturellen Registerzugriffsstruktur. Beispiele für nichtmediostrukturelle Register sind das nachspanninterne „Register der Ehrengäste vom 1. bis 360. MundartFrühschoppen" in Herwig (2005) und das so genannte Elementenregister in Karbelaschwili (2007) (vgl. dazu 4.). 
Register, die durchgängig in ihren Registereinträgen mindestens eine Registerverweisangabe aufweisen, haben mindestens einen indirekten Registerzugriffsbereich. Dieser wird durch die mediostrukturelle Orientierung der Registerverweisangaben festgelegt. Die Register, zu denen die Registerausschnitte (1) und (2) sowie (4)-(7) in Abb. 1 gehören, weisen alle einen indirekten Zugriffsbereich auf. Sie gehören daher zum Typ des mediostrukturellen Registers. Mediostrukturelle Register haben eine mediostrukturelle Registerzugriffsstruktur. Sie heißen auch Zugriffsregister. Dieser Typenname ist durch den Sachverhalt motiviert, dass mit den Registerverweisangaben Außenadressen genannt werden, die dem Benutzer Zugriff auf die Zugriffssektoren des indirekten Zugriffsbereich eröffnen, weswegen Verweisadressen auch Zugriffsadressen heißen. In Wörterverzeichnissen sind die Zugriffssektoren die Wörterbuchartikel.

Mediostrukturelle Register können mehrere Zugriffsbereiche aufweisen. Wird in den Registereinträgen auf eine andere Textverbundkonstituente verwiesen und auch auf andere Registereinträge, wie z.B. in dem Sachregister von Paul (2002; vgl. (4) in Abb. 1 u. (8) in Abb. 2), dann hat das Register sich selbst auch als indirekten Zugriffsbereich, und die Registerzugriffsstruktur wird zur verweisdurchlässigen Zugriffsstruktur (i.S.v. Wiegand 2008). Mediostrukturelle Register mit gerade einem Registerzugriffsbereich heißen monodirektionale Zugriffsregister, solche mit mehreren Zugriffsbereichen heißen polydirektionale Zugriffsregister. Mehrere mediostrukturelle Register, die den gleichen Zugriffsbereich aufweisen, heißen äquidirektionale Zugriffsregister. Das NLO (1997) hat acht äquidirektionale Zugriffsregister: Alle sind Äquivalentregister und haben das Wörterverzeichnis als indirekten Registerzugriffsbereich. Das Deutsche Fremdwörterbuch hat fünf äquidirektionale Zugriffsregister: Ein alphabetisches (vgl. (12) in Abb. 8), ein rückläufiges, ein chronologisches (vgl. (19) in Abb. 14), ein Herkunftsregister (vgl. (20) in Abb. 14) und ein Wortklassenregister.

Der Typ des mediostrukturellen Registers weist zahlreiche Untertypen auf. Die wichtigsten Register in Printwörterbüchern sind die zentralen alphabetischen Zugriffsregister. Diese heißen zentral, weil ihr indirekter Registerzugriffsbereich das zentrale Wörterverzeichnis ist. Beispiele für solche Register sind die Wörterbuchregister, zu denen die Registerausschnitte (1) und (2) sowie (4)-(7) in Abb. 1 gehören, sowie die Register, zu denen (9) in Abb. 2 und (11)-(14) in Abb. 8 gehören. Weitere Beispiele für alphabetische zentrale Register sind das Register im Nachspann von Brunner und Moritz (1997), das Register im Nachspann von Augst (1984 und 2003), das nachspanninterne Wortregister in Riehme (1980) sowie das nachspanninterne Register in Schröder (1992). Der registervermittelte Zugriff, der durch alphabetische zentrale Register ermöglicht wird, kann über folgende äußere Zugriffsstrukturen erfolgen:

über die alphabetische Hauptzugriffsstruktur: Mit den Registerverweisangaben werden lemmatische Verweisadressen genannt, wie z.B. in (11) in Abb. 8. 
- $\quad$ über die Seitenzahlzugriffsstruktur: Mit den Registerverweisangaben werden Seitenzahlen als numerische Verweisadressen genannt, wie z.B. in (6) in Abb. 1.

- $\quad$ über die Seitenzahlzugriffsstruktur mit nachgeordneter Zeilenzahlzugriffsstruktur: Die Registerverweisangaben sind numerische Doppeladressenangaben, mit denen als Hauptadresse eine Seitenzahl und als Unteradresse eine Zeilenzahl genannt wird.

- $\quad$ über die Spaltenzahlzugriffsstruktur mit nachgeordneter Zeilenzahlzugriffsstruktur: Die Registerverweisangaben sind numerische Doppeladressenangaben, mit denen als Hauptadresse eine Spaltenzahl und als Unteradresse eine Zeilenzahl genannt wird, wie z.B. in (13) in Abb. 8.

- $\quad$ über die alphanumerische Kopfzeilenzugriffsstruktur in Sachgruppenwörterbüchern: Mit den Registerverweisangaben werden die Sachgruppennummer und der zugehörige Artikeltitel genannt, wie z.B. in (5) in Abb. 1.

Neben dem Typ des zentralen alphabetischen Zugriffsregisters lässt sich der Typ des peripheren alphabetischen Zugriffsregisters unterscheiden, der mehrere Untertypen aufweist. Register dieses Typs haben als indirekten Registerzugriffsbereich Umtexte oder Einschübe. Beispiele für periphere alphabetische Zugriffsregister sind: Das vorspanninterne Register zum Umtext mit dem Umtexttitel „Einführung in die Terminologie“ in Kluge und Seebold (1995); weiterhin das vorspanninterne Register mit dem Titel "Stichwortregister zur lexikographischen Einleitung" im FWB-1 sowie das Register zur "Lexikographischhistorischen Einführung“ in Dornseiff (2004) und das „Register zum Vorwort" in WDG-1. Ein peripheres alphabetisches Zugriffsregister zur "Systematischen Einführung" wird sich auch im „Wörterbuch zur Lexikographie und Wörterbuchforschung" (WLWF) finden (vgl. Wiegand 2003a) sowie in allen geplanten WSK-Bänden (vgl. Schierholz und Wiegand 2005). Alle genannten peripheren alphabetischen Zugriffsregister gehören zum Untertyp des umtextorientierten alphabetischen Zugriffsregisters.

Eine weitere typologische Unterscheidung ist gegeben mit dem Typ des orientierenden und dem des nichtorientierenden Zugriffsregisters. Ein orientierendes alphabetisches Zugriffsregister weist nicht nur Fundortdaten in der Form unterschiedlicher Registerverweisangaben auf, sondern auch andere Angaben, so dass angereicherte Registereinträge gegeben sind; oder es sind bifunktionale Angaben gegeben wie in den Äquivalentregistern. Entsprechend haben orientierende Register adressen- und inhaltsvermittelnde Registerzugriffsstrukturen. Meistens sind orientierende Zugriffsregister zentrale alphabetische Register. Der Registerausschnitt (7) in Abb. 1 stammt aus einem zentralen orientierenden alphabetischen Register; ebenso der Registerausschnitt (12) in Abb. 8 sowie (16) in Abb. 14. Die inhaltliche Orientierung, die ein Benutzer anhand eines orientierenden Zugriffsregisters erhält, kann er vor der Ausfüh- 
rung einer Verweisbefolgungshandlung erschließen. Anders ausgedrückt heißt das: Ein orientierendes Zugriffsregister ermöglicht die Erschließung von Antworten auf bestimmte Suchfragen, ohne dass das zentrale Wörterverzeichnis oder eine andere Textverbundkonstituente registervermittelt konsultiert wird. Ein Benutzer, der z.B. lediglich wissen möchte, wie die offizielle Staatsbezeichnung von Syrien ist, erhält die Antwort anhand einer Registerangabe des Registers, aus dem der Ausschnitt (16) stammt. Zentrale orientierende alphabetische Zugriffsregister treten in unterschiedlichen Ausprägungen auf. Alle zweisprachigen Äquivalentregister, z.B. die in NLO (1997), gehören zu den zentralen orientierenden alphabetischen Zugriffsregistern. Für alle Äquivalentregister ist charakteristisch, dass mit ihrer Hilfe Antworten auf Suchfragen vom Typ WIE LAUTET DAS ÄQUIVALENT ZU EINEM AUSDRUCK DER SPRACHE X IN EINER SPRACHE Y? erhältlich sind.

Nichtorientierende Zugriffsregister, die auch reine Zugriffsregister heißen, weisen adressenvermittelnde Registerzugriffsstrukturen auf. Die Register, zu denen die Registerausschnitte (1), (2), (4) und (6) in Abb. 1 gehören, sind beispielsweise zentrale nichtorientierende alphabetische Zugriffsregister. Auch periphere Register können nichtorientierende Zugriffsregister sein. Beispielsweise ist das Register, aus dem (10) in Abb. 2 stammt, ein peripheres nichtorientierendes alphabetisches Zugriffsregister.

Die meisten Registerzugriffsstrukturen sind glatte äußere Zugriffsstrukturen, so dass auf der Trägermenge auch eine textarchitektonische oberhalbRelation definiert ist; das gilt z.B. für die Register, aus denen die Registerausschnitte (1), (2) und (4)-(6) in Abb. 1 oder auch für die Register, aus denen (16) und (18) in Abb. 14 stammen. Neben den glatten Registerzugriffsstrukturen treten jedoch auch gestaffelte Registerzugriffsstrukturen auf (vgl. Wiegand 2008). Diese bestehen aus einer vorgeordneten Registerzugriffsstruktur, sowie $n$ nachgeordneten Registerzugriffsstrukturen (mit $n>1$ ). Bei gestaffelten äußeren Zugriffsstrukturen, heißt die vorgeordnete Zugriffsstruktur auch primäre Zugriffsstruktur und die nachgeordnete Zugriffsstruktur sekundäre Zugriffsstruktur. Die Registerzugriffsstruktur des Chronologischen Registers in Kirkness (1988) ist eine gestaffelte Registerzugriffsstruktur (vgl. (19) in Abb. 14). Die vorgeordnete Registerzugriffsstruktur ist alphanumerisch. Ihre Registereingänge sind entweder Jahreszahlen, wie z.B. „1150“ oder alphanumerische Ausdrücke der Form „11. Jh.“. Die nachgeordneten Registerzugriffsstrukturen sind alle glattalphabetisch. Die Registerzugriffsstruktur des Chronologischen Registers in Kirkness (1988) gehört daher zum Typ der gestaffelten alphanumerischchronologischen/alphabetischen Registerzugriffsstruktur. - Auch das Herkunftsregister in Kirkness (1988) hat eine gestaffelte Registerzugriffsstruktur (vgl. (20) in Abb. 14); Diese gehört zu einem anderen Untertyp, und zwar zum Typ der gestaffelten alphabetischen/alphabetischen Registerzugriffsstruktur. Sowohl die vorgeordneten Registereingänge, z.B. Ägyptisch, Algonkin, Arabisch, Babylonisch (die auch Hauptregistereingänge heißen), als auch nachgeordneten Registereingänge (die auch Unterregistereingänge heißen) sind alpha- 
betisch geordnet, und zwar im Registerausschnitt (20) striktinitialalphabetisch. - Schließlich weist auch das Wortklassenregister in Kirkness (1988) eine gestaffelte Registerzugriffsstruktur auf (vgl. (21) in Abb. 15).

(21)

Nomen als Bestimmungswort

Detail-

Malefiz-

Pleinair-

Radio-

Sanität-

Statutar-

Synthetik-

Tele-

Teleskop-

Tropik-

Nomen als Grundwort

-technie

(23)

csatol 54

csatolt tartományok 80

csökkentett járulékfizetés 338

csökkentett (összegü) nyugdíj 224

csökkent munkaképesség 132, 339

csökkent munkaképességü 126, 131

csökkent munkaképességüek járadéka

297
(22)

Märchen

Medien

Meistergesang

Metapher

Metrik

Mimesis

Minnesang

Mittelalterrezeption

Mittellateinische Literatur

Moderne

Mündlichkeit/Schriftlichkeit

Mystik

Mythos

(24)

$\begin{array}{lr}\text { brevitas } & 0436 \\ \text { brisare } & 0440 \mathrm{a}^{*} \\ \text { brocchus } & 0440 \mathrm{~b} \\ \text { bruma } & 0441 \mathrm{a} \\ \text { \{bruscum } & 0441 \mathrm{~b}\} \\ \text { brutalis (brutus) } & 0442 \\ \text { bubalus (bufalus) } & 0449 \\ \text { bucca (buccula) } & 0428 \\ \text { buccula } & 0445,1671 \\ \text { bucina } & 2735 \mathrm{a} \\ \text { bufo } & 0450 \\ \text { bulga } & 0448\end{array}$

Abb. 15: Registerausschnitt (21) aus dem Wortklassenregister in Kirkness (1988); (21) $=\mathrm{re}_{197}-\mathrm{re}_{213}$. Ausschnitt (22) aus dem "Verzeichnis der Artikel" aus Brunner und Moritz (1997). Registerausschnitt (23) aus Ildikó (2005); (23) = $\mathrm{re}_{214}-\mathrm{re}_{220}$. Registerausschnitt (24) aus Kytzler und Redemund (2007); $\mathrm{re}_{221}-\mathrm{re}_{232}$.

Bei der äußeren Zugriffsstruktur des Wortklassenregisters in Kirkness (1988) handelt es sich ebenfalls um eine Registerzugriffsstruktur vom Typ der gestaffelten alphabetischen/alphabetischen Registerzugriffsstruktur. Mit den Hauptregistereingängen werden Termini für Wortklassen genannt und mit den Unterregistereingängen Ausdrücke, die zur jeweiligen Wortklasse gehören. Die Unterregistereingänge sind verweisvermittelnde Registereingänge.

In manchen Wörterbüchern finden sich alphabetische Listen, die lediglich aus Eingängen bestehen. Ein Beispiel ist die „Liste der Wortbildungselemente, die in der alphabetischen Stichwortliste erscheinen" in Duden-10, aus der (3) in Abb. 1 stammt. Ein weiteres Beispiel ist das vorspanninterne alphabetische „Verzeichnis der Artikel" in Brunner und Moritz (1997), aus dem (22) in Abb. 
15 stammt. Schließlich sei als letztes Beispiel die nachspanninterne alphabetische Liste in Götz und Wellmann (2007) genannt, die mit "Definitionswortschatz" überschrieben ist. Solche Listen finden sich in zahlreichen Lernerwörterbüchern.

Für solche Listen gibt es m.E. zwei Möglichkeiten für eine angemessene lexikographietheoretische Deutung. Entweder handelt es sich um ein reduziertes alphabetisches Register, also um ein Register ohne Registerangaben, oder es liegt ein rudimentäres lexikographisches Inhaltsverzeichnis vor, in dem die Nennung der Seitenzahlzugriffsstruktur fehlt. Welche der beiden Möglichkeiten vorliegt, entscheiden die jeweiligen textuellen Gegebenheiten in dem Wörterbuch. Moritz und Brunner (1997) ist ein Fachwörterbuch, das relativ wenige (nämlich 144) umfangreiche Fachwörterbuchartikel aufweist. Dem vorspanninternen alphabetischen Artikelverzeichnis (vgl. die M-Strecke in (22) in Abb. 15) kann daher die genuine Funktion zugewiesen werden, dem Benutzer einen schnellen Überblick über die Fachwörterbuchartikel zu ermöglichen. Die gleiche Funktion hätte ein lexikographisches Inhaltsverzeichnis. Da in Moritz und Brunner (1997) ein nachspanninternes ausführliches alphabetisches Register literaturwissenschaftlicher Termini existiert, liegt in diesem Fall eine Deutung nahe, das Artikelverzeichnis, auch weil es alle Artikel nennt und damit einen Bezug zum Ganzen hat, als rudimentäres lexikographisches Inhaltsverzeichnis aufzufassen. Im übrigen gilt, dass der Status des Rudimentären nur strukturell gegeben ist. Funktional gesehen, besteht er nicht, da ein alphabetisch geordnetes rudimentäres lexikographisches Inhaltsverzeichnis einen lemmagenauen Zugriff gestattet.

Die „Liste der Wortbildungselemente, die in der alphabetischen Stichwortliste erscheinen" (vgl. (3) in Abb. 1), die sich - nebenbei bemerkt - auch im Vorspann des Duden-DaF findet — lässt sich nicht als rudimentäres lexikographisches Inhaltsverzeichnis deuten; ihr fehlt der Bezug zum gesamten Textverbund. Mit einer alphabetischen Liste der als Lemmata angesetzten Wortbildungselemente (nämlich der Affixe und Affixoide) werden automatisch auch die zugehörigen Affix- und Affixoidartikel aufgelistet, so dass ein partielles Artikelverzeichnis gegeben ist. Dieses lässt sich als reduziertes Register auffassen, dessen Reduzierung darin besteht, dass auf die Registereingänge keine Registerangaben folgen. Die Registerinformation, die insgesamt erhältlich ist, besteht darin, dass ein Benutzer erfährt, welche Wortbildungsmittel als Lemmata angesetzt sind sowie für ein spezifisches Suchinteresse darin, ob ein bestimmtes Wortbildungsmittel als Lemma angesetzt ist oder nicht. - Auch die alphabetische Liste des Definitionswortschatzes kann als reduziertes alphabetisches Register aufgefasst werden. Register - so hatten wir gesehen - sind entweder mediostrukturell oder nichtmediostrukturelle Register. Daher entsteht die Frage, zu welchem der beiden Typen die reduzierten alphabetischen Register als Untertypen gehören. Angenommen ein Benutzer möchte wissen, ob das Wort Basis zum Definitionswortschatz von Götz und Wellmann (2007) gehört. Dann kann er mit dem Leitelement | Basis | eine Benutzungshandlung vom Typ der externen Registerzugriffshandlung ausführen. Wenn er den Re- 


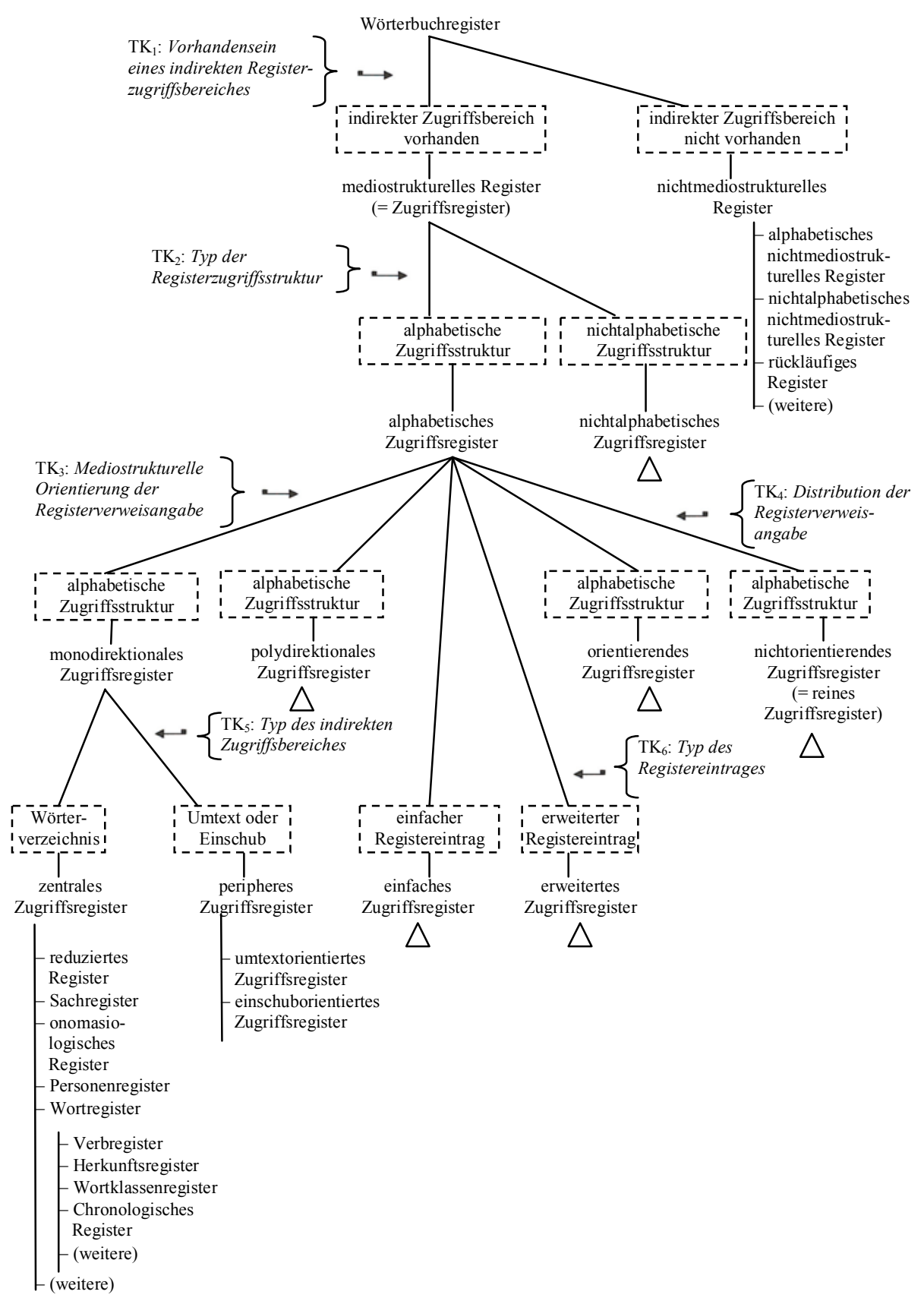

Abb. 16: Partiell kommentierter Typologiegraph zu einem Ausschnitt aus einer Typologie von Wörterbuchregistern 
gistereingang „Basis“ gefunden hat und möchte nun z.B. wissen, ob die Bedeutungsparaphrase zu Basis, die mit der Bedeutungsparaphrasenangabe im Wörterbuchartikel zu Basis genannt wird, nur mit Wörtern aus der Liste, 'Definitionswortschatz' formuliert ist, dann muss er zuerst im Wörterbuchartikel mit dem Lemma Basis die Bedeutungsparaphrasenangabe suchen. Da der Benutzer von dem reduzierten alphabetischen Register zum Lemma Basis gehen muss, lässt sich die Benutzungshandlung, die er ausführen muss, als registervermittelte externe Verweisbefolgungshandlung auffassen. Diese Auffassung setzt voraus, dass die Registereingänge von reduzierten alphabetischen Registern, mit deren Registereingängen Lemmata erwähnt werden, als verweisvermittelnde Registereingänge gelten, so dass sich folgender Vorschlag ergibt: Reduzierte alphabetische Register, mit deren Registereingängen Lemmata erwähnt werden, gelten als mediostrukturelle Register; ihr indirekter Registerzugriffsbereich sind Wörterverzeichnisse. Dagegen gelten reduzierte alphabetische Register - wie z.B. das „Register der Ehrengäste vom 1. bis 360. Mundart-Frühschoppen" in Herwig (2005) - als nichtmediostrukturelle Register; sie weisen nur einen reduzierten Registerzugriffsbereich auf, der aus der Menge aller Registereingänge besteht, mit denen keine Lemmata erwähnt werden.

Im Abb. 16 fassen wir zunächst die unterschiedenen Registertypen zu einem Typologieausschnitt zusammen.

Von den Definitionen, die zu dem Typologieausschnitt in Abb. 16 gehören, seien die beiden Folgenden genannt:

(D-5: zentrales Zugriffsregister)

Ein zentrales Zugriffsregister ist ein alphabetisches monodirektionales Wörterbuchregister, dessen indirekter Zugriffsbereich das Wörterverzeichnis ist.

(D-6: erweitertes Register)

Ein erweitertes Register ist ein alphabetisches Zugriffsregister in einem Wörterbuch, das erweiterte Registereinträge aufweist.

Der Abschnitt sei beendet mit einem Ausschnitt aus einer Typologie von Registerzugriffsstrukturen (vgl. auch Wiegand 2008).

Von den Definitionen, die zu dem Typologieausschnitt in Abb. 17 gehören, seien die beiden Folgenden genannt:

(D-7: alphabetische zentrale mediostrukturelle Registerzugriffsstruktur) Eine alphabetische zentrale mediostrukturelle Registerzugriffsstruktur ist eine mediostrukturelle Zugriffsstruktur eines zentralen alphabetischen Zugriffsregisters, deren indirekter Registerzugriffsbereich das zentrale Wörterverzeichnis ist.

(D-8: alphabetische nichtmediostrukturelle Registerzugriffsstruktur) Eine alphabetische nichtmediostrukturelle Registerzugriffsstruktur ist eine Registerzugriffsstruktur, deren Registereingänge alphabetisch geordnet sind und die keinen indirekten Registerzugriffsbereich aufweist. 


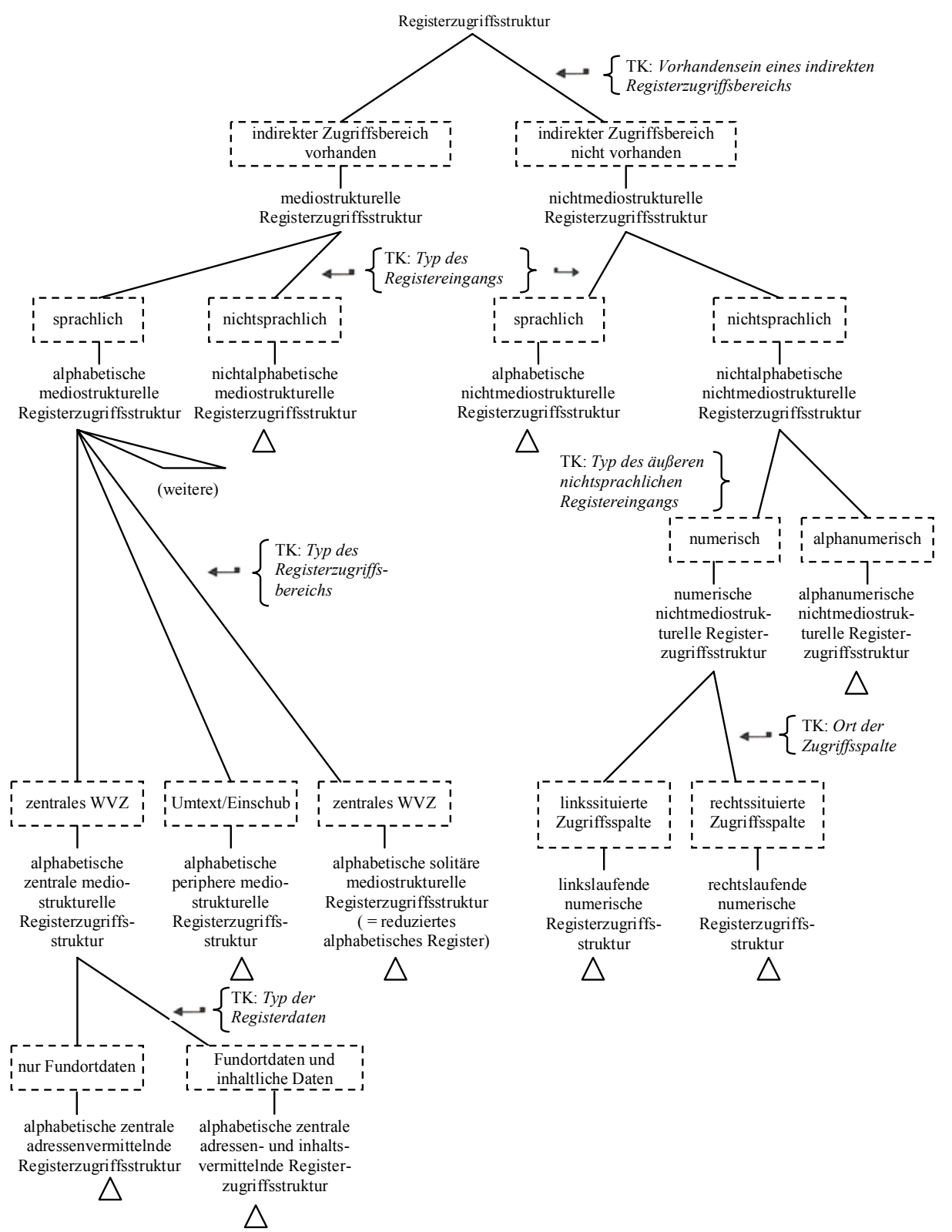

Abb. 17: Kommentierter Typologiegraph zu einem Ausschnitt aus einer Typologie von Registerzugriffsstrukturen; Abkürzung: WVZ = Wörterverzeichnis 


\section{Registerfunktionen}

Unter einer Registerfunktion wird eine Funktion (i.S.v. Aufgabe) verstanden, die ein Register im Rahmen des gesamten Printwörterbuchs hat. Die jeweilige Funktion eines Registers wird erstens wesentlich bestimmt von den Eigenschaften, die das Wörterbuch hat, zu dem das Register gehört und damit vom jeweiligen Wörterbuchtyp. Zweitens bestimmt der jeweilige Registertyp die Registerfunktion.

Zunächst gilt allgemein stets das Folgende: Da jedes Register eine Registerzugriffsstruktur aufweist und da alle Registerzugriffsstrukturen äußere Zugriffsstrukturen sind, leistet jedes Register einen Beitrag zur externen Datenakzessivität des Wörterbuchs, zu dem es gehört. Will man unterschiedliche Registerfunktionen bestimmen und näher charakterisieren, muss man daher den jeweiligen Beitrag eines Registers zur externen Datenakzessivität spezifizieren, und zwar unter Berücksichtigung des Wörterbuchtyps und des Registertyps.

Wir betrachten zunächst alphabetische zentrale Zugriffsregister, also solche monodirektionalen Register, deren indirekter Registerzugriffsbereich ein Wörterverzeichnis ist und beginnen mit alphabetischen zentralen Zugriffsregistern in so genannten onomasiologischen Wörterbüchern, die auch unter anderen Typennamen bekannt sind, wie z.B. systematisches Wörterbuch (vgl. z.B. Friederich 1966). Ein Ausschnitt aus dem alphabetischen zentralen Zugriffsregister im Dornseiff (2004) ist (5) in Abb. 1. Weitere Beispiel sind das „Alphabetische Register der Mundartwörter" sowie das "Alphabetische Register hochdeutscher Stichwörter" in dem Dialektwörterbuch nach Sachgruppen (Meng 1986). Solche Register, deren indirekter Zugriffsbereich ein Wörterverzeichnis ohne alphabetische makrostrukturelle Zugriffsstruktur ist, haben folgende Registerfunktion: Sie garantieren erstens die einzige alphabetische Zugriffsmöglichkeit auf alle Daten im Wörterverzeichnis und weisen zweitens - wie alle mediostrukturellen Register - eine Findefunktion auf. Genau die gleichen Registerfunktionen haben alphabetische zentrale Zugriffsregister in Wörterbüchern mit randomisierter Makrostruktur, wie z.B. Prosinger (1984).

In alphabetischen Wörterbüchern sind alle lemmatischen Angaben primär akzessiv; alle nichtlemmatischen Angaben sind sekundär akzessiv; auf die Letzteren kann daher nur zugegriffen werden, wenn vorher auf das Lemma zugegriffen wurde. Alphabetische zentrale Zugriffsregister in alphabetischen Wörterbüchern haben erstens die Funktion, dass auf die sekundär akzessiven Daten indirekt extern zugegriffen werden kann; ihre alphabetisch geordneten Registereingänge nennen daher nichtlemmatische Angaben, die zu einem oder mehreren Angabetypen je wörterbuchspezifischer Klassen von Angaben gehören. Welche Angabetypen das sind, ist meistens aus dem Registertitel ersichtlich. Es folgen einige Beispiele: Das zentrale alphabetische Zugriffsregister in Pfeifer (1993) hat den Titel: „Verzeichnis nicht an alphabetischer Stelle behandelter Wörter“. Ein Registereintrag lautet: „abprotzen Protze“. Ein Benutzer, der 
anhand dieses Registereintrages einen Registerverweis erschließt und mit Hilfe des mediostrukturellen Leitelements |Protzel eine Verweisbefolgungshandlung dadurch ausführt, dass er eine externe Registerzugriffshandlung ausführt, findet nach dem externen Zugriff auf das Lemma Protze im zugehörigen Wörterbuchartikel das nicht an alphabetischer Stelle lexikographisch bearbeitete sekundär akzessive Wort "a b p r o t z e n“, das am Schluss des Artikels wie folgt bearbeitet ist:

a b p r o t z e n Vb 'ein Geschütz von der Protze abheben und in Feuerstellung bringen` (Anfang 18. Jh.) 'ein Geschütz abfeuern` (18. Jh.).

Die wörterbuchspezifische Klasse von Angaben, zu der ",a b p r o t z e n“ und alle mit den anderen Registereingängen genannten Angaben gehören, wird im Registertitel genannt; es ist die wörterbuchspezifische Klasse der "nicht an alphabetischer Stelle behandelten Wörter". - Das zentrale alphabetische Zugriffsregister in Seibicke (1989) trägt den Titel „Register der in den Wörterbuchartikeln erwähnten gemeinsprachlichen und landschaftlichen Ausdrücke". Aus diesem Register stammen die Registerausschnitte (1) und (2) in Abb. 1. Auch in diesem Register werden die sekundär akzessiven Angaben und dazu Teile von Angabetexten mit den Registereingängen genannt. Unter systematischen Aspekten sind die Register in Pfeifer (1993) und Seibicke (1989) gleichartig, und zwar auch hinsichtlich ihrer Registerfunktion. Beide weisen eine Findefunktion auf, die darin besteht, dass auf artikelinterne sekundär akzessive Daten, die zu einer wörterbuchspezifischen Klasse gehören, extern zugegriffen werden kann. Die Klassen können verschieden sein: Beispielsweise sind die Elemente der Klasse in Pfeifer (1993) wortbildungsmorphologisch zusammengehörige Wörter und in Seibicke (1989) sind es meistens Varietätenäquivalente. Der Terminus Findefunktion ist so zu verstehen, das ein Register, das eine Findefunktion aufweist, dem Benutzer ermöglicht im Registerzugriffsbereich Daten zu finden und nicht etwa so, dass der Benutzer im Register etwas findet.

An dieser Stelle sei nun ausdrücklich gesagt, dass es gerade nicht die Aufgabe einer Registertheorie sein kann, alle inhaltlichen Möglichkeiten aufzulisten, die empirisch vorgefunden werden können. Vielmehr besteht die Aufgabe gerade darin, das strukturelle und funktionale Gemeinsame inhaltlich unterschiedlicher Fälle begrifflich zu erfassen. Für den Typ des zentralen alphabetischen Registers in alphabetischen Wörterbüchern mit Findefunktion für artikelintern sekundär akzessiven Daten, gibt es unzählige Ausprägungsmöglichkeiten, die sich nur dadurch unterscheiden, zu welcher Klasse die sekundär akzessiven Daten gehören, die mittels des Registers gefunden werden können. Bei der Planung von Registern kommt es daher darauf an, aus der großen Zahl dieser Möglichkeiten angemessen auszuwählen. Kriterien für eine begründete Auswahl sind erhältlich, wenn man überlegt, welche Register etwas dazu beitragen, die dem Wörterbuch zugeordneten Wörterbuchfunktionen (i.S.v. Wiegand 2001) besser zu erfüllen.

In alphabetischen Wörterbüchern treten weiterhin auch alphabetische 
zentrale Register auf, die eine andere als die gerade behandelte Registerfunktion haben. Es handelt sich um die reduzierten Register, mit deren Registereingängen Lemmata genannt werden, wie z.B. in dem Register, aus dem (3) in Abb. 1 ein Registerausschnitt ist. In Sprachwörterbüchern sind Register dieses Typs relativ selten; im Sachwörterbüchern sind sie nach meinem Eindruck öfters anzutreffen. Beispielsweise findet man in Sportlexika reduzierte Personenregister, in denen die Namen der Sportler alphabetisch aufgelistet sind, die einen Personenartikel mit ihrem Namen als Lemma erhalten haben. Solche Register haben eine Registerfunktion, die man als Übersichtsfunktion zu einer Menge von ausgewählten Wörterbuchartikeln betrachten kann.

Im Folgenden betrachten wir alphabetische periphere Zugriffsregister am Beispiel eines umtextorientierten Zugriffsregisters. Der Registerausschnitt (10) in Abb. 2 stammt aus einem Register dieses Typs. Es ist das von mir erarbeitete "Register zur lexikographisch-historischen Einführung" im Dornseiff (2004). Dieses Zugriffsregister funktioniert wie ein Sach- und Personenregister in einer fachlichen Monographie. Es dient also der Auffindung von Textstellen anhand von Termini und Namen und hat damit eine Finde- und Inhaltserschließungsfunktion.

Als nächstes werden die orientierenden Zugriffsregister kurz betrachtet. Während in nichtorientierenden Zugriffsregister auf die Registereingänge ausschließlich Registerverweisangaben folgen, so dass nichtorientierende Zugriffsregister nur eine Findefunktion aufweisen, treten in orientierenden Zugriffsregistern auch angereicherte Registereinträge auf, wie beispielsweise in dem Register, aus dem der Registerausschnitt (9) in Abb. 1 stammt. Orientierende Zugriffsregister haben daher nicht nur eine Findefunktion. Vielmehr erhält der Benutzer auf bestimmte Suchfragen eine inhaltliche Antwort allein anhand der Registerangaben. Aus diesem Grund heißt die Registerzugriffsstruktur von alphabetischen zentralen orientierenden Zugriffsregistern auch alphabetische zentrale adressen- und inhaltsvermittelnde Registerzugriffsstruktur. Die orientierenden Zugriffsregister haben mithin neben der Finde- eine Auskunftsfunktion. Damit sind die wichtigsten der mediostrukturellen Register hinsichtlich ihrer Registerfunktionen behandelt, und wir werfen noch einen kurzen Blick auf die nichtmediostrukturellen Register.

Für alle nichtmediostrukturellen Register gilt — da sie keine Zugriffsregister sind - dass sie keine Findefunktion aufweisen. Sie haben nur einen direkten Zugriffsbereich, in dem der Benutzer Daten direkt auffinden kann. In einem rückläufigen Register, das nur Registereingänge aufweist, kann er viele Wörter finden, die auf -at enden. Daher gilt: Alle nichtmediostrukturellen Register weisen ausschließlich eine themengebundene Auskunftsfunktion auf. - Zusammenfassend kann also festgestellt werden: Alle mediostrukturellen Register weisen eine Findefunktion auf. Einige mediostrukturelle Register, die zu bestimmten Registertypen gehören, weisen zusätzlich eine Auskunfts- oder eine Inhaltserschließungsfunktion auf. Alle nichtmediostrukturellen Register haben nur eine Auskunftsfunktion. Alle Register tragen etwas dazu bei, dass 
die externe Datenakzessivität erweitert wird. Alle alphabetischen zentralen Zugriffsregister machen ein alphabetisches Printwörterbuch polyakzessiv.

\section{Registerkritik}

Das in diesem Beitrag bereitgestellte begriffliche Instrumentarium kann auch genutzt werden, um an vorhandenen Registern begründet hinsichtlich ihrer Anlage und hinsichtlich ihrer Funktionen Kritik zu üben und Verbesserungsvorschläge zu machen. Dies sei im Folgenden an einem Beispiel gezeigt.

Das „Lexikon zur Wortbildung der deutschen Sprache (Augmentation und Diminution)" (Karbelaschwili 2001), das für Benutzer gedacht ist, die Deutsch als Fremdsprache lernen, ist ein Lehrstück dafür, wie ein Wörterbuchregister nicht angelegt sein sollte. Das Wörterbuch ist sachlich gegliedert und weist somit eine nichtformgeprägte Makrostruktur auf. Die sachliche Gliederung geht aus dem Ausschnitt des Inhaltsverzeichnisses hervor, der in Abb. 18 zu sehen ist.

\section{(25)}

1. Augumentation

\begin{tabular}{|c|c|}
\hline 1.1 & Substantiv ..................... \\
\hline 1.1.1 & Adposition ........ \\
\hline 1.1.2 & Postposition .............. \\
\hline 1.2 & Adjektiv ...................... \\
\hline 1.2 .1 & Adposition .................... \\
\hline 1.2 .2 & Postposition ................ \\
\hline 1.3 & 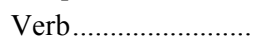 \\
\hline 1.3 .1 & Adposition .................... \\
\hline
\end{tabular}

\begin{tabular}{|c|c|c|c|}
\hline \multicolumn{4}{|c|}{ 1. Diminution } \\
\hline 22 & 2.1 & Substantiv......................... & 140 \\
\hline 22 & 2.1 .1 & Adposition.................... & 140 \\
\hline 71 & 2.1 .2 & 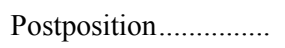 & 151 \\
\hline 85 & 2.2 & Adjektiv ......................... & 154 \\
\hline 85 & 2.2 .1 & 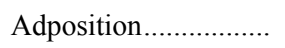 & 154 \\
\hline 132 & 2.2 .2 & Postposition .................... & 158 \\
\hline 134 & 2.3 & 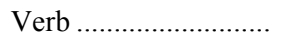 & 159 \\
\hline 134 & 2.3 .1 & Adposition........................ & 159 \\
\hline & 2.3 .2 & Postposition.................... & 161 \\
\hline
\end{tabular}

Abb. 18: Ausschnitt aus dem lexikographischen Inhaltsverzeichnis von Karbelaschwili (2001)

Karbelaschwili (2001) weist eine gestaffelte numerischsachbezogene/alphabetische Zugriffsstruktur auf. Ein Benutzer, der ein Affix oder Affixoid nachschlagen möchte, kann das nur dann, wenn er in der Lage ist, das Affix oder Affixoid in das sachliche System einzuordnen, denn obwohl es sich um ein nichtalphabetisches Wörterbuch handelt, hat es kein alphabetisches Zugriffsregister. Angenommen, ein Benutzer möchte das augmentative Präfixoid Bärennachschlagen, dann muss er es zunächst richtig klassifizieren, so dass er weiß, dass er Bären- unter 1.1.1 (vgl. Abb. 18) suchen muss. Das externe Zugreifen verläuft dann wie folgt: Erst muss der Benutzer im lexikographischen Inhaltsverzeichnis die Seitenzahl ermitteln, dann muss er auf die genannte Seite 22 zugreifen und danach auf den Sachgruppentitel. Innerhalb der Sachgruppe findet der Benutzer dann eine alphanumerische äußere Doppelzugriffsstruktur, die z.B. folgende äußeren Zugriffstextelemente aufweist: 
<1. ASS- , 2. AB- , 3. ABER- , 4. ADLER- , 5. AFFEN- , 6. AFTER- , ..., 21. BÄREN- , ..., 281 ZENTRAL- >.

Jede Sachgruppe hat eine eigene Zugriffsstruktur dieser Art. Die vorgeordnete numerische Zugriffsstruktur ist allerdings akzessiv funktionslos, denn sie wird in einem Zugriffsregister nicht genutzt; darin besteht aber gerade der Sinn einer alphanumerischen äußeren Doppelzugriffsstruktur, wie man in Ildikó (2005) sehen kann (vgl. Registerausschnitt (23) in Abb. 15). Statt eines Zugriffregisters weist Karbelaschwili (2001) ein so genanntes (nichtmediostrukturelles) Elementenregister auf, das ein reduziertes Register ist und mithin nur aus Registereingängen besteht. In diesem sind die Sachgruppentitel, die Affixe und Affixoide genau so angeordnet, wie in der Makrostruktur! In dem Register kann nicht ohne weiteres nachgeschlagen werden. Vielmehr muss der Benutzer die gleiche klassifikatorische Vorarbeit leisten, die er erbringen muss, wenn er im Wörterverzeichnis nachschlagen möchte; erst danach kann er in elf aufeinander folgenden Teilen, die jeweils alphabetisch sind, systematisch suchen. Was er nach erfolgreicher Suche findet, ist dann allerdings nichts weiter als das Affix! Die Registerinformation, die erhältlich ist, besteht mithin nur darin, dass das Affix primär gebucht ist!

Richtig und akzessiv funktional wäre es gewesen, wenn man die Lemmata vollständig und damit sachgruppenübergreifend durchnummeriert und dann ein alphabetisches Zugriffsregister angelegt hätte, in dessen Registereinträgen die Lemmanummern mit einer numerischen Registerverweisangabe genannt werden. Die Registereinträge hätten dann folgende Form: Aas- 1 , Ab- 2 , aber3 , Adler- 4 , -affe 5, Affen- 5. Dies wären mithin einfache reduzierte Registereinträge. Ein alphabetisches zentrales Zugriffsregister dieser Art macht die klassifikatorische Vorarbeit des Benutzers überflüssig und erlaubt den schnellen punkgenauen registervermittelten Zugriff auf alle Affixe und Affixoide. Statt der einfachen reduzierten kann man auch erweiterte angereicherte Registereinträge folgender Form anlegen: „Aas- 1; Aug. Subst. Adpos." (mit „Aug.“ als Abkürzung für Augmentation; mit "Subst." als Abkürzung für Substantiv und mit "Adpos." als Abkürzung für Adposition). Dann hätte das Register nicht nur eine Findefunktion, sondern auch eine eigenständige Auskunftsfunktion, da Antworten auf Fragen nach der Klassenzugehörigkeit erhältlich sind.

\section{Schlussbemerkung}

Nach meiner Kenntnis der empirischen Basis, die freilich in einem Beitrag dieser Art nur recht fragmentarisch präsentiert werden kann, reichen die hier dargestellten Grundlagen einer Theorie der Register wahrscheinlich aus, um jedes vorgelegte Wörterbuchregister lexikographietheoretisch erklären und einordnen zu können, das zu einem Printwörterbuch gehört, das in einer Sprache verfasst ist, die mittels einer Alphabetschrift so verschriftet ist, dass die zugehörigen Texte eine dextograde Schriftrichtung aufweisen. 


\section{Literatur}

Augst, Gerhard. 1984. Kinderwort. Der aktive Kinderwortschatz (kurz vor der Einschulung) nach Sachgebieten geordnet mit einem alphabetischen Register. Frankfurt a.M. [etc.]: Peter Lang.

Augst, Gerhard. 2003. Dialektwörterbuch der Verbandsgemeinde Altenkirchen. Wölmersen: Arbeitskreis für Heimatgeschichte und Brauchtumspflege e.V.

Blair, Ann. 2000. Annoting and Indexing Natural Philosophy. Frasca-Spada, M. und N. Jardine (Hrsg.). Books and the Sciences in History: 69-89. Cambridge: Cambridge University Press.

Bratschi, Armin und Rudolf Trüb. 1991. Simmentaler Wortschatz. Wörterbuch der Mundart des Simmentals (Berner Oberland / Mit einer grammatischen Einleitung und mit Registern. Unter Mitarbeit v. Lily Trüb sowie v. Maria Bratschi u. Ernst Max Perren. Zeichnungen v. Rolf Oberhäusli. Grammatiken und Wörterbücher des Schweizerdeutschen in allgemeinverständlicher Darstellung. Bd. XII. Thun: Ott Verlag.

Brunner, Horst und Rainer Moritz. (Hrsg.). 1997. Literaturwissenschaftliches Lexikon. Grundbegriffe der Germanistik. Berlin: Erich Schmidt.

Bustos Plaza, Alberto und Herbert Ernst Wiegand. 2006. Condensación textual lexicográfica: esbozo de una concepción integral. Revista de Lexicografía 12: 7-46.

Dobel, Richard (Hrsg.). 1972. dtv-Lexikon der Goethe-Zitate. Bd. 1: A-N; Bd. 2: O-Z. München: Deutscher Taschenbuchverlag.

Dornseiff, Franz. 2004. Der deutsche Wortschatz nach Sachgruppen. 8., völlig neu bearb. und mit einem vollständigen alphabetischen Zugriffsregister versehene Aufl. von Uwe Quasthoff. Mit einer lexikographisch-historischen Einführung und einer ausgewählten Bibliographie zur Lexikographie und Onomasiologie von Herbert Ernst Wiegand. Berlin/New York: Walter de Gruyter.

Duden-DaF = Dudenredaktion (Hrsg.). 2002. Standardwörterbuch Deutsch als Fremdsprache. Mannheim [etc.]: Dudenverlag.

Duden ${ }^{-4}$ GFWB $=$ Wiss. Rat der Dudenredaktion (Hrsg.). 2007. Duden. Das große Fremdwörterbuch . Herkunft und Bedeutung der Fremdwörter. 4., aktual. Aufl. Mannheim [etc.]: Bibliographisches Institut \& F.A. Brockhaus AG.

Duden-GW = Duden. 1976-1981. Das große Wörterbuch der deutschen Sprache in sechs Bänden. Hrsg. und bearb. vom Wissenschaftlichen Rat und den Mitarbeitern der Dudenredaktion unter der Leitung von Günther Drosdowski. Mannheim [etc.]: Bibliographisches Institut.

Duden-10 = Dudenredaktion (Hrsg.). 2002. Duden. Das Bedeutungswörterbuch. 3., neu bearb. u. erw. Aufl. Der Duden in zwölf Bänden. Bd. 10. Leipzig/Wien/Zürich: Dudenverlag.

Erk, Heinrich. 1972. Zur Lexik wissenschaftlicher Fachtexte. Verben — Frequenz und Verwendungsweise. Schriften der Arbeitsstelle für wissenschaftliche Didaktik des Goethe-Instituts 4. München: Max Hueber.

Eymer, Wilfrid. 1997. Eymers Pseudonymen Lexikon. Realnamen und Pseudonyme in der deutschen Literatur. Teil 1: Realnamen mit den verwendeten Pseudonymen. Teil 2: Pseudonyme mit Verweisen auf die Realnamen. Bonn: Kirschbaum Verlag.

Friederich, Wolf. 1966. Moderne deutsche Idiomatik. Systematisches Wörterbuch mit Definitionen und Beispielen. München: Max Hueber. 
FWB-1 = Anderson, Robert R., Ulrich Goebel und Oskar Reichmann (Hrsg.). Frühneuhochdeutsches Wörterbuch. Bd. 1: Einführung, a-äpfelkern. Bearb. v. Oskar Reichmann. Berlin/New York: Walter de Gruyter.

FWB 8/1 = Goebel, Ulrich und Oskar Reichmann (Hrsg.). 1997. Frühneuhochdeutsches Wörterbuch. Begr. v. R. R. Anderson, U. Goebel, O. Reichmann. Bd. 8. Lief. $1 i$, j. Bearb. v. V. Winge. Berlin. New York: Walter de Gruyter.

Götz, Dieter und Hans Wellmann (Hrsg.). 2007. Langenscheidt. Taschenwörterbuch Deutsch als Fremdsprache. Das einsprachige Lernerwörterbuch für Einsteiger. Neubearbeitung. In Zusammenarbeit mit der Langenscheidt-Redaktion. Berlin [etc.]: Langenscheidt.

Hartmann, R.R.K. und Gregory James. 1998. Dictionary of Lexicography. London/New York: Routledge.

Heinzmann, Wilhelm. 1993. Wörterbuch der Pflanzennamen im Altwestnordischen. Ergänzungsbände zum Reallexikon der Germanischen Altertumskunde. Bd. 7. Berlin. New York: Walter de Gruyter.

Helbig, Gerhard und Wolfgang Schenkel. 1980. Wörterbuch zur Valenz und Distribution deutscher Verben. Leipzig: VEB Bibliographisches Institut.

Herwig, Axel. 2005. Das Kasseler Mundartwörterbuch. Überarb. v. N. Rose, E. Reppel und E. Schmidt. Gudensberg-Gleichen: Wortberg Verlag.

Herzog, Hans-Ulrich und Georg Hannes. 1990. Lexikon Flaggen und Wappen. Leipzig: VEB Bibliographisches Institut.

Ildikó, Fata. 2005. Ungarisch-Deutsches/Deutsch-Ungarisches Fachwörterbuch zur Rentenversicherung. Szeged: Grimm Kiadó.

Karbelaschwili, Samson. 2001. Lexikon zur Wortbildung der deutschen Sprache (Augmentation und Diminution). 2. korrig. u. erw. Aufl. Materialien Deutsch als Fremdsprache 51. Regensburg: Armin Wolff. Univ. Regensburg.

Kirkness, Alan (Hrsg.). 1988. Deutsches Fremdwörterbuch. Begonnen v. Hans Schulz, fortgeführt v. Otto Basler, weitergeführt im Institut für deutsche Sprache. 7. Bd. Berlin/New York: Walter de Gruyter.

Kluge, Friedrich. 1943. Etymologisches Wörterbuch der deutschen Sprache. 12. u. 13. unveränd. Aufl. Mit Unterstützung durch W. Krause bearb. v. A. Götze. Berlin/Leipzig: Walter de Gruyter.

Kluge, Friedrich und Elmar Seebold. 1995. Etymologisches Wörterbuch der deutschen Sprache. 23. erw. Aufl. Berlin/New York: Walter de Gruyter.

Kytzler, Bernhard und Lutz Redemund. 2007. Unser tägliches Latein. Lexikon des lateinischen Spracherbes. 7. Aufl. Mainz: Philipp von Zabern.

Meng, Heinrich. 1986. Mundartwörterbuch der Landschaft Baden im Aargau nach Sachgruppen. Grammatiken und Wörterbücher des Schweizerdeutschen in allgemeinverständlicher Darstellung. Bd. X. Baden: Baden Verlag.

Müller, Wolfgang. 1973. Duden. Leicht verwechselbare Wörter. Mannheim/Wien/Zürich: Dudenverlag.

NLO 1997 = Bergenholtz, Henning, Ilse Cantell, Ruth Vatvedt, Dag Gundersen, Jón Hilmar Jónsson und Bo Svensén. Nordisk Leksikografsk Ordbog. Skrifter utgitt av Nordisk forening for leksikografi 4. Oslo: Universitetsforlaget AS. 
Paul, Hermann. 2002. Deutsches Wörterbuch. Bedeutungsgeschichte und Aufbau unseres Wortschatzes. 10. überarb. u. erw. Aufl. v. Helmut Henne, Heidrun Kämper und Georg Objartel. Tübingen: Max Niemeyer.

Pfeffer, J. Alan. 1987. Deutsches Sprachgut im Wortschatz der Amerikaner und Engländer. Vergleichendes Lexikon mit analytischer Einführung und historischem Überblick. Tübingen: Max Niemeyer.

Pfeifer, Wolfgang. 1993. Etymologisches Wörterbuch des Deutschen. 1. Bd. A-L; 2. Bd.: M-Z. 2. Aufl. durchges. und erg. v. Wolfgang Pfeifer. Berlin: Akademie Verlag.

Prosinger, Wolfgang. 1984. Das rabenstarke Lexikon der Scene-Sprache. Der große Durchblick für alle Freaks, Spontis, Schlaffis, Softies, Flipper und Hänger sowie deren Verwandte und sonstige Fuzzis. Illustriert von P. Gaymann. Frankfurt am Main: Eichborn Verlag.

Riehme, Joachim. 1990. Gleich gesprochen — verschieden geschrieben. Zum Verwechseln ähnliche Wörter und ihre richtige Schreibung. Leipzig: VEB Bibliographisches Institut.

Rouse, Mary und Richard H. Rouse. 1982. La naissance des index. Martin, H.-J. und R. Chartier (Hrsg.). Histoire d'édition française: 77-85. Paris: Promodes.

Scheuplein-Fritz, M., A. König, S. Krämer-Neubert und N.R. Wolf (Hrsg.). 1996. Wörterbuch von Unterfranken. Eine lexikographische Bestandsaufnahme. Würzburg: Könighausen \& Neumann.

Schierholz, Stefan und Herbert Ernst Wiegand. 2005. Die Wörterbücher zur Sprach- und Kommunikationswissenschaft. Eine neue Konzeption der linguistischen Fachlexikographie und ihre computergestützte Praxis. Lexicographica 20: 164-264.

Schröder, Jochen. 1992. Lexikon deutscher Präfixverben. Berlin [etc.]: Langenscheidt. Verlag Enzyklopädie.

Seibicke, Wilfried. 1989. Duden. Wie sagt man anderswo? Landschaftliche Unterschiede im deutschen Sprachgebrauch. 2. neu bearb. u. erw. Aufl. Duden-Taschenbücher. Bd. 15. Mannheim/Wien/ Zürich: Dudenverlag.

WDG-1 = Klappenbach, Ruth und Wolfgang Steinitz (Hrsg.). 1974. Wörterbuch der deutschen Gegenwartssprache. 1. Bd: A-deutsch. Bearb.: R. Klappenbach u. H. Malige-Klappenbach. 7. Aufl. Berlin: Akademie-Verlag.

Wiegand, Herbert Ernst. 1983. Was ist eigentlich ein Lemma? Ein Beitrag zur Theorie der lexikographischen Sprachbeschreibung. Wiegand, H.E. (Hrsg.). Studien zur neuhochdeutschen Lexikographie III: 401-474. Germanistische Linguistik 1-4/82. Hildesheim/Zürich/New York: Georg Olms Verlag.

Wiegand, Herbert Ernst. 1995. Lexikographische Texte in einsprachigen Lernerwörterbüchern. Kritische Überlegungen anlässlich des Erscheinens von Langenscheidts Großwörterbuch Deutsch als Fremdsprache. Popp, Heidrun (Hrsg.). Deutsch als Fremdsprache. An den Quellen eines Faches. Festschrift für Gerhard Helbig zum 65. Geburtstag: 463-499. München: Judicium Verlag.

Wiegand, Herbert Ernst. 1998. Wörterbuchforschung. Untersuchungen zur Wörterbuchbenutzung, zur Theorie, Geschichte, Kritik und Automatisierung der Lexikographie. 1. Teilband. Mit 159 Illustrationen im Text. Berlin/New York: Walter de Gruyter.

Wiegand, Herbert Ernst. 1998a. Altes und Neues zur Makrostruktur in alphabetischen Printwörterbüchern. Wiegand, H.E. (Hrsg.). Wörterbücher in der Diskussion III. Vorträge aus dem Heidelberger Lexikographischen Kolloquium: 348-372. Lexicographica. Series Maior 84. Tübingen: Max Niemeyer. 
Wiegand, Herbert Ernst. 1998b. Lexikographische Textverdichtung. Entwurf einer vollständigen Konzeption. Zettersten, Arne, Viggo Hjørnager Pedersen und Jens Erik Mogensen (Hrsg.). 1998. Symposium on Lexicography VIII. Proceedings of the Eighth International Symposium on Lexicography, May 2-4, 1996, at the University of Copenhagen: 1-35. Lexicographica. Series Maior 90. Tübingen: Max Niemeyer.

Wiegand, Herbert Ernst. 2000. Adressierung in der ein- und zweisprachigen Lexikographie. Eine einführende Übersicht über die Forschungs- und Problemlage. Lexikos 10: 32-74.

Wiegand, Herbert Ernst. 2000a. Über tabellarische Wörterverzeichnisse und deren Wörterbuchartikel. Ein Beitrag zur Theorie der Wörterbuchform. Lexicographica 16: 212-234.

Wiegand, Herbert Ernst. 2001. Was eigentlich sind Wörterbuchfunktionen? Kritische Anmerkungen zur neueren und neusten Wörterbuchforschung. Lexicographica 17: 217-248.

Wiegand, Herbert Ernst. 2002. Altes und Neues zur Mediostruktur in Printwörterbüchern. Lexicographica 18: 168-252.

Wiegand, Herbert Ernst. 2002a. Adressierung in zweisprachigen Printwörterbüchern. Wiegand, H.E. (Hrsg.). 2002. Studien zur zweisprachigen Lexikographie mit Deutsch VIII: 111-175. Germanistische Linguistik 166. Hildesheim/Zürich/New York: Georg Olms Verlag.

Wiegand, Herbert Ernst. 2003. Überlegungen zur Typologie von Wörterbuchartikeln in Printwörterbücher. Ein Beitrag zur Theorie der Wörterbuchform. Lexicographica 19: 169-313.

Wiegand, Herbert Ernst. 2003a. Wörterbuch zur Lexikographie und Wörterbuchforschung/Dictionary of Lexicography and Dictionary Research. Städtler, Th. (Hrsg.). 2003. Wissenschaftliche Lexikographie im deutschsprachigen Raum. Im Auftrag der Heidelberg Akademie der Wissenschaften: 417-437. Heidelberg: Winter Verlag.

Wiegand, Herbert Ernst. 2005. Über die Datenakzessivität in Printwörterbüchern. Einblicke in neuere Entwicklungen einer Theorie der Wörterbuchform. Lexikos 15: 196-230.

Wiegand, Herbert Ernst. 2005a. Angaben, funktionale Angabezusätze, Angabetexte, Angabestrukturen, Strukturanzeiger, Kommentare und mehr. Ein Beitrag zur Theorie der Wörterbuchform. Lexicographica 21: 202-379.

Wiegand, Herbert Ernst. 2006. Das Lern- und Konsultationswörterbuch. Ein neuer Fachwörtertyp am Beispiel der Wörterbücher zur Sprach- und Kommunikationswissenschaft (WSK). Lexikos 16: 205-221.

Wiegand, Herbert Ernst. 2006a. Adressierung in Printwörterbüchern. Präzisierungen und weiterführende Überlegungen. Lexicographica 22: 187-261.

Wiegand, Herbert Ernst. 2007. Über Zugriffspfade in Printwörterbüchern. Ein Beitrag zur Schnittstselle von Benutzungshandlungen und Wörterbuchform. Lexikos 17: 180-211.

Wiegand, Herbert Ernst. 2008. Zugriffsstrukturen in Printwörterbüchern. Ein zusammenfassender Beitrag zu einem zentralen Ausschnitt einer Theorie der Wörterbuchform. Lexicographica 24. [erscheint.]

Zedelmaier, Helmut. 2004. „Facilitas inveniendi“. Zur Pragmatik alphabetischer Buchregister. Stammen, Th. und W.E.J. Weber (Hrsg.). Wissenssicherung, Wissensordnung und Wissensverarbeitung. Das europäische Modell der Enzyklopädien: 191-203. Colloquia Augustana. Bd. 18. Berlin: Akademie Verlag.

Zehetner, Ludwig. 1997. Bairisches Deutsch. Lexikon der deutschen Sprache in Altbayern. München: Heinrich Hugendubel. 